

\section{Dynamic Analysis of an Inflatable Dam Subjected to a Flood}

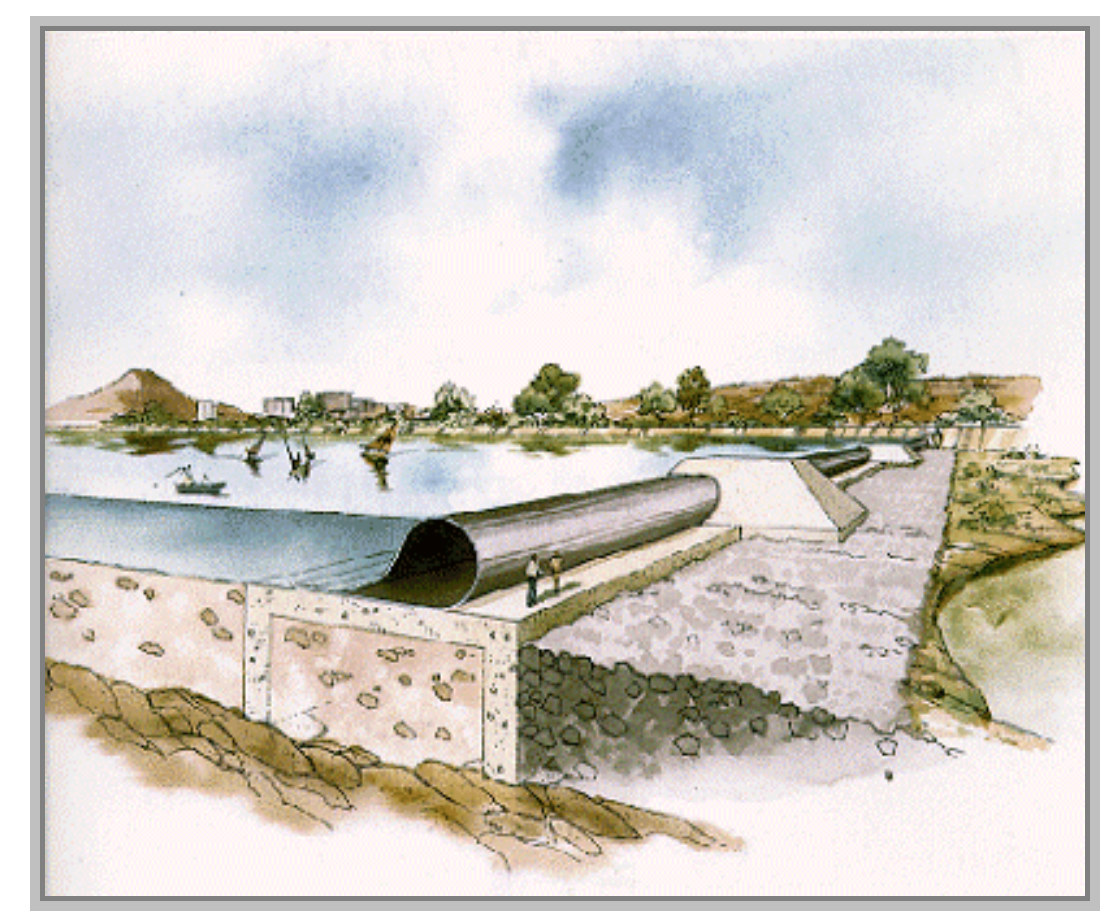

Artist's rendition of the inflatable dam being built to create a 220 surface-acre man made lake in Tempe Arizona. This illustration was reproduced from the Tempe City web site.

\section{(Abstract)}

A dynamic simulation of the response of an inflatable dam subjected to a flood was carried out to determine the survivability envelope of the dam where it can operate without rupture, or overflow. A fully nonlinear free-surface flow was applied in two dimensions using a mixed Eulerian-Lagrangian formulation. An ABAQUS finite element model was used to determine the dynamic structural response of the dam. The problem was solved in the time domain which allows the prediction of a number of transient phenomena such as the generation of upstream advancing waves, and dynamic structural collapse. Stresses in the dam material were monitored to determine when rupture occurs. An iterative study was performed to find the service envelope of the dam in terms of the internal pressure and the flood Froude number for two flood depths. It was found that the driving parameter governing failure of the dam was the 
internal pressure. If this pressure is too low, the dam overflows; if this pressure is too high, the dam ruptures.

The fully nonlinear free-surface flow over a semi-circular bottom obstruction was studied numerically in two dimensions using a similar solution formulation as that used in the previous study. A parametric study was performed for a range of values of the depth-based Froude number up to 2.5 and non-dimensional obstacle heights up to 0.9 . When wave breaking does not occur, three distinct flow regimes were identified: subcritical, transcritical and supercritical. When breaking occurs it may be of any type: spilling, plunging or surging. In addition, for values of the Froude number close to 1, the upstream solitary waves break. A systematic study was undertaken, to define the boundaries of each type of breaking and non-breaking pattern, and to determine the drag and lift coefficients, free surface profile characteristics and transient behavior. 


\section{Acknowledgments}

Dr. Stergios Liapis has provided a great deal of encouragement and support for this project. He has been there for me when I needed guidance, confirmation of accuracy, or a sounding board for my ideas. He is also making a special effort to attend my defense of this thesis and serve as my committee co-chairman. For all this and more, he has my appreciation and gratitude.

I would like to acknowledge Premkumar Muthedath and Linda Constantine for their assistance in developing the numerical potential flow code. It was from their foundation that the numerical aspects of this project were built.

I would like to thank Jeff Cullina and Jason Dare for their help in performing the multitude of test runs required for the parametric study of flow over a semicircular obstruction. I would also like to thank Tristan Keller for helping me make the preliminary runs necessary to characterize the response in the case of an inflatable dam. With the help of these young engineers, I was able to take this project further than my original goals.

Finally, I would like give thanks to my committee members, Dr. Raymond Plaut, Dr. Eric Johnson, and Dr. Wane Neu for their upcoming patience while they read over this thesis and hear my defense.

This research was partially supported by a grant from the National Science Foundation (grant No. CMS-9422248). 


\section{Preface}

This thesis is in the form of two distinct parts. In Chapter I, Dynamic Structural Analysis of an Inflatable Dam Subjected to a Flood, the dynamic response of a typical dam without overflow is predicted. This is the normal operating mode for an inflatable dam, and dictates the important design parameters of the structure. The original intention for this study was to include the analysis of a flexible inflatable dam under slight to moderate overflow conditions. It was discovered that the resulting flow contained wave breaking and vorticity. Unfortunately, the potential flow solution method used was not applicable for these conditions. A numerical study was carried out to predict wave breaking in the flow over a bottom obstruction. This study is included here as Chapter II, Free Surface Flow Over A Semi-Circular Obstruction. Although this second study does not relate well to inflatable dams, it does further the literature in flows over bottom obstructions. It may also assist future authors in the prediction of the dynamic response of an inflatable dam under overflow conditions. 


\section{Table of Contents}

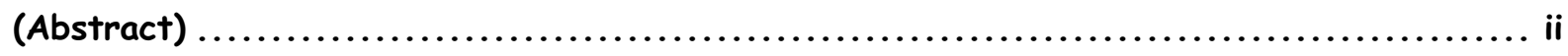

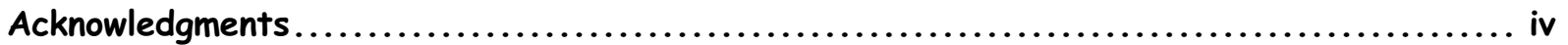

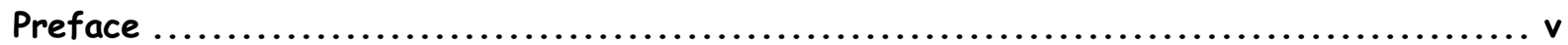

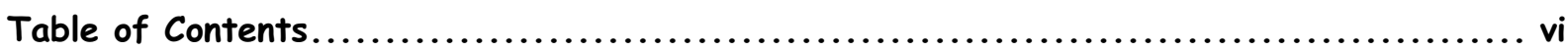

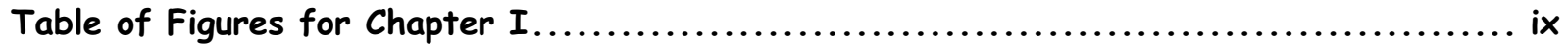

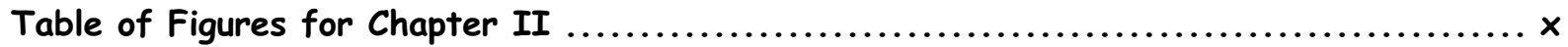

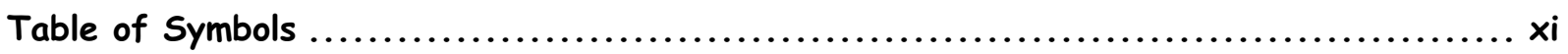

PART I Dynamic Analysis of an Inflatable Dam Subjected to a Flood.......... I

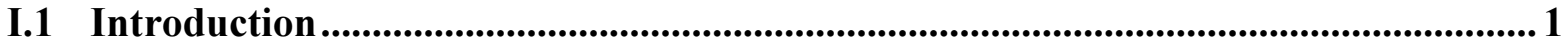

I.2 Two - dimensional fluid - structure interaction study ..........................................5

I.2.1 Mathematical Formulation of the Fluid Flow ..................................................... 5

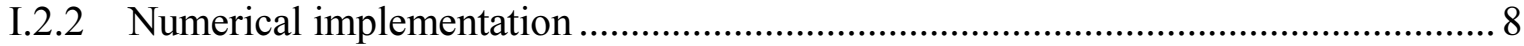

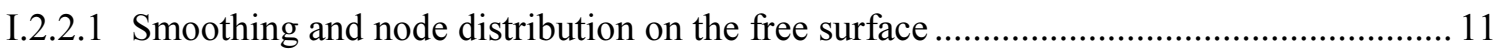

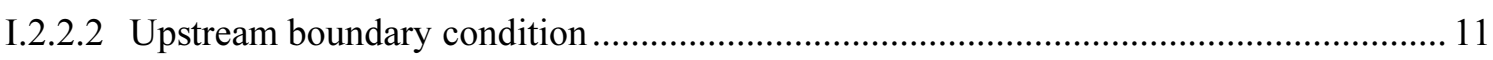

I.2.2.3 Calculation of the pressure acting on the dam.......................................................... 13

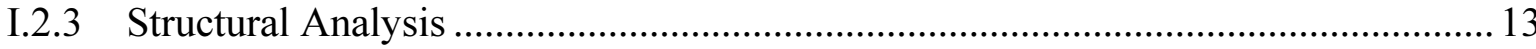

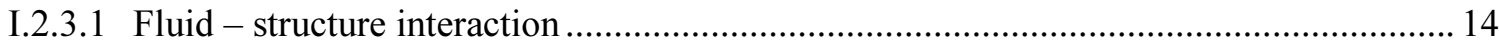

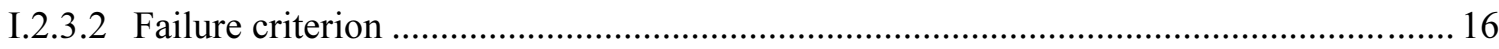

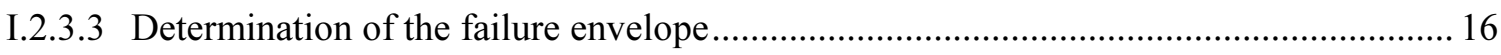

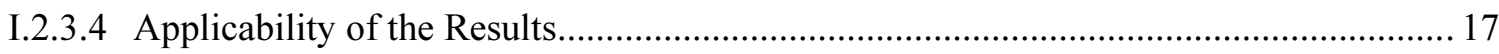

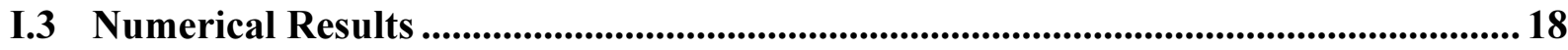

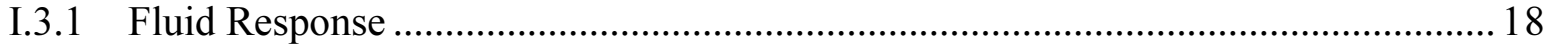

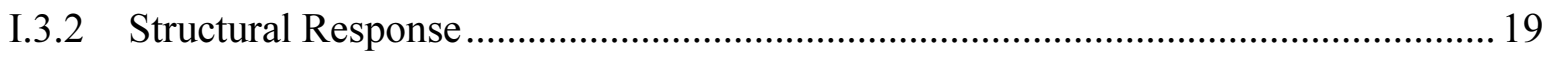

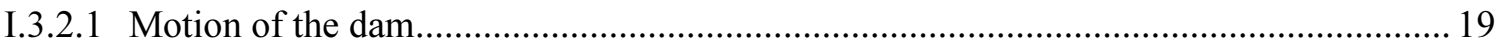

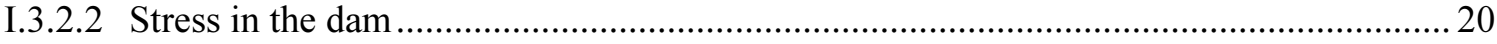

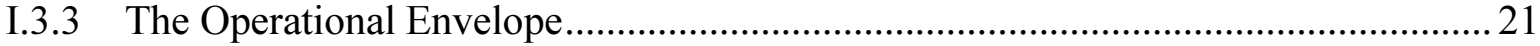

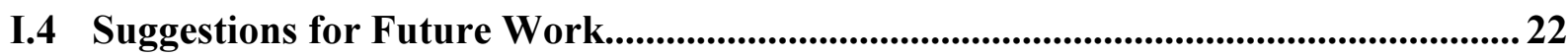

I.5 Conclusions ............................................................................................................................................. 23

PART II Free Surface Flow Over A Semi-Circular Obstruction.............. 24 


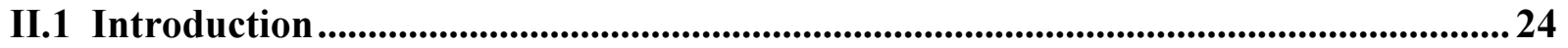

II.2 Two - dimensional fluid flow parametric study ......................................................... 28

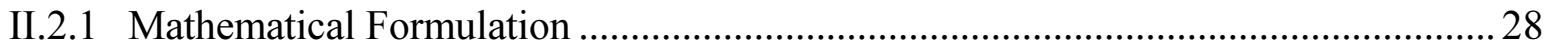

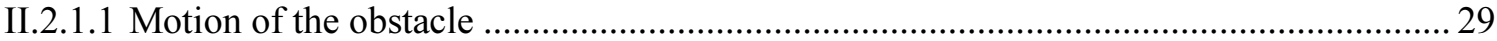

II.2.1.2 Discretization of the Numerical Tank ...................................................................... 29

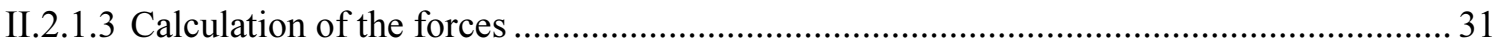

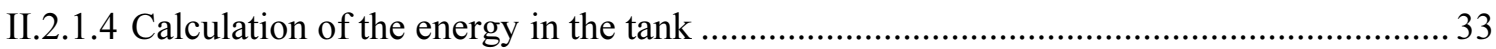

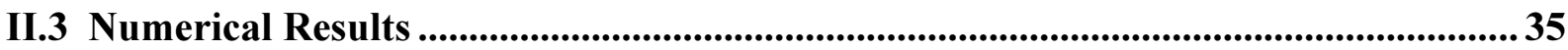

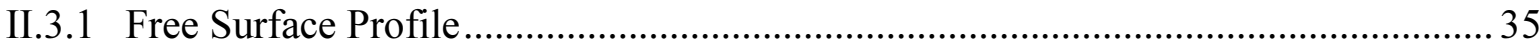

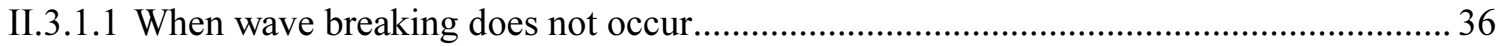

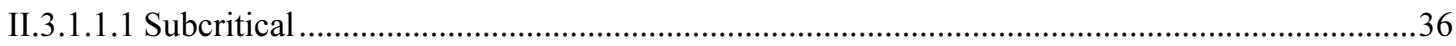

II.3.1.1.2 Transcritical ....................................................................................................................

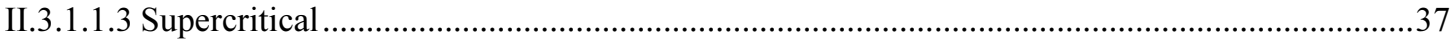

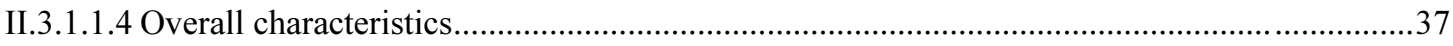

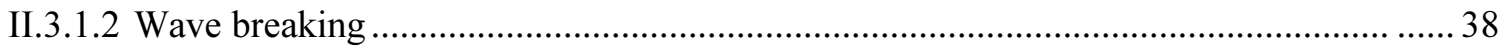

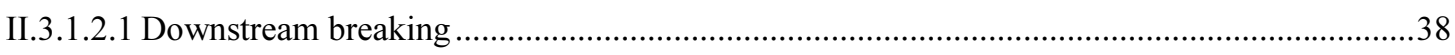

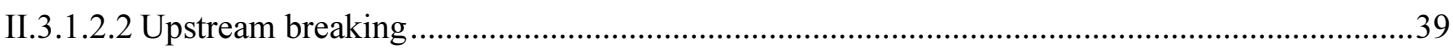

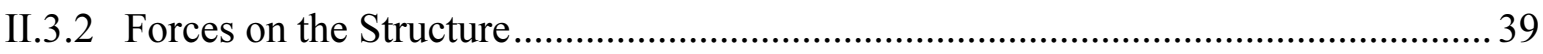

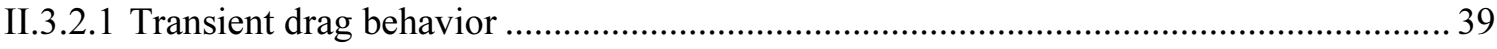

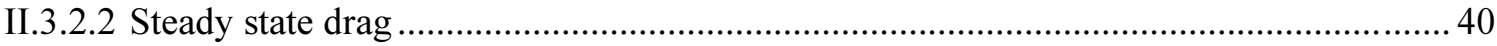

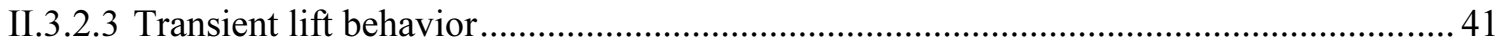

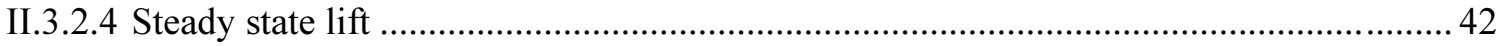

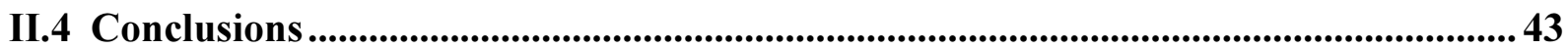

Appendix A: ABAQUS Static Analysis Model .................................. 44

Appendix B: ABAQUS Dynamic Analysis Restart File ........................... 47

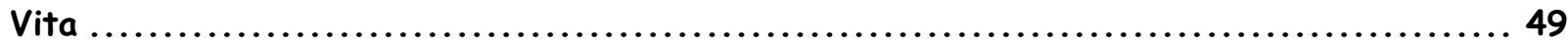




\section{Table of Figures for Chapter I}

Figure I-1: Sketch of a typical inflatable dam illustrating some basic parameters influencing dam

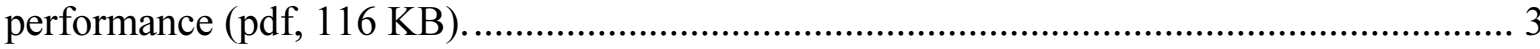

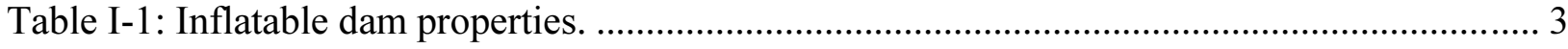

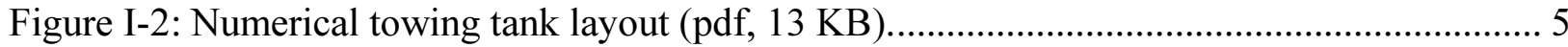

Figure I-3: Flow chart of the solution method for the no-overflow case (pdf, $15 \mathrm{~KB})$............. 14

Figure I-4: Solving the fluid structure interaction problem (pdf, 19 KB) ............................... 14

Figure I-5: Sample displacement profile for an inflatable dam in a flood (JPEG, 234 KB)....... 18

Figure I-6: Sample displacement - time profile plot of the free surface and an inflatable dam

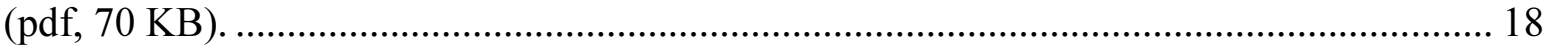

Figure I-7: Plot of the free surface response for a tall rigid dam (pdf, $27 \mathrm{~KB}) \ldots \ldots \ldots \ldots \ldots \ldots \ldots \ldots . . . . . . . . . .18$

Figure I-8: Sample displacement profile for an inflatable dam during overflow (JPEG, $166 \mathrm{~KB}$ ).

Figure I-9: Trace of several nodes on the surface of an oscillating inflatable dam (pdf, 20 KB). 19

Figure I-10: The motion of the uppermost node of an oscillating inflatable dam as a function of

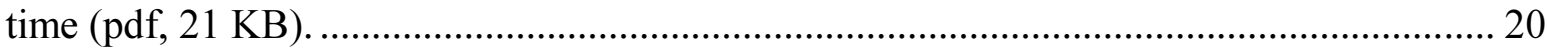

Figure I-11: Plot of the static stress in the dam for a low inflation pressure (pdf, $4 \mathrm{~KB}$ ).......... 20

Figure I-12: Plot of the static stresses in the dam for an inflation pressure that would cause the

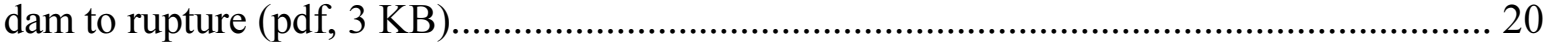

Figure I-13: Dynamic stresses at a point on the top of the dam (pdf, $23 \mathrm{~KB})$........................ 21

Figure I-14: Serviceability envelope for a flood depth of two meters (pdf, $10 \mathrm{~KB}$ )................. 21

Figure I-15: Serviceability envelope for a flood depth of three meters (pdf, $10 \mathrm{~KB}$ )................ 21 


\section{Table of Figures for Chapter II}

Figure II-1: The steady state flow regimes (pdf, $45 \mathrm{~KB})$................................................... 25

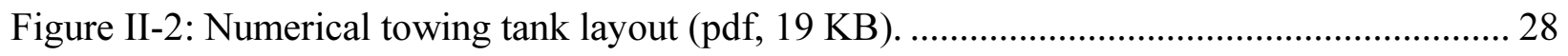

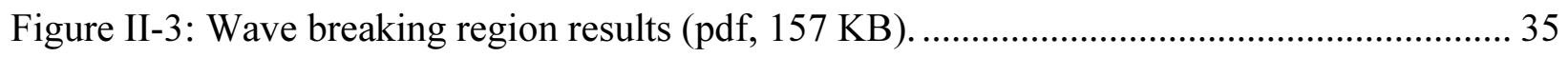

Figure II-4: Sample free surface profile plot for subcritical flow (pdf, $108 \mathrm{~KB})$..................... 36

Figure II-5 Sample free surface profile plot for transcritical flow (pdf, $67 \mathrm{~KB}$ ). .................. 37

Figure II-6: Sample free surface profile plot for supercritical flow (pdf, $32 \mathrm{~KB})$................... 37

Figure II-7: Plot of the height of the initial upstream advancing soliton as a function of the nondimensional obstacle height $\alpha$ for different values of the Froude number (pdf, $8 \mathrm{~KB}$ )....... 37

Figure II-8: Sample free surface profile plot of a spilling type breaking wave (pdf $17 \mathrm{~KB})$....... 38

Figure II-9: Sample free surface profile plot of a plunging type breaking wave (pdf, $15 \mathrm{~KB}$ )... 38

Figure II-10: Sample free surface profile plot of a surging type breaking wave (pdf, $16 \mathrm{~KB}$ ) .... 38

Figure II-11: Sample free surface profile plot of an upstream breaking wave (pdf, 14 KB)....... 39

Figure II-12: Plot of the lift and drag coefficients on the structure, as functions of time, for

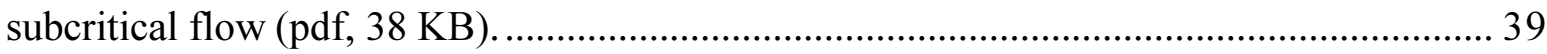

Figure II-13: Plot of the lift and drag coefficients on the structure, as functions of time, for

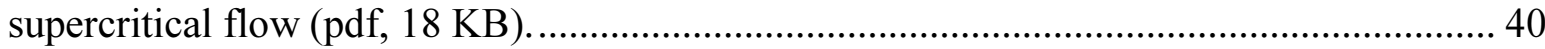

Figure II-14: Plot of the steady state drag as a function of non-dimensional obstacle height for various Froude numbers (pdf, $25 \mathrm{~KB})$...................................................................... 41

Figure II-15: Plot of the steady state lift as a function of the structure for various Froude numbers

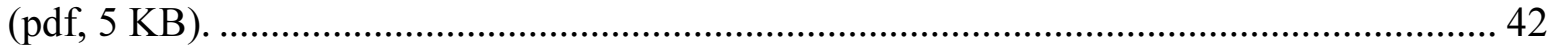




\section{Table of Symbols}

h, $\mathrm{d}$

The initial upstream water height (depth)

L. Tank length for the fluid solution

$F n \equiv \frac{U_{B}}{\sqrt{g \cdot h}} \ldots \ldots . .$. Froude number (non-dimensional velocity)

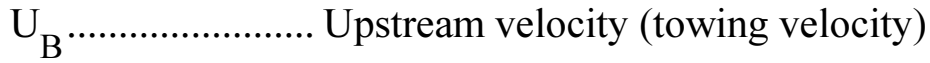

R ....................... Semi-circular obstruction height (radius)

g ....................... The acceleration due to gravity

$\rho$....................... Density of water

$\alpha \equiv \frac{R}{h} \ldots \ldots \ldots \ldots \ldots . . . . .$. Non-dimensional dam or obstruction height

t........................... Time

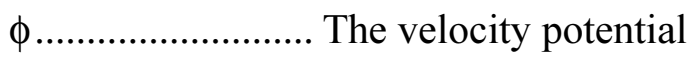

$\psi$........................ The stream function

$\nabla$....................... The gradient operator

$\mathrm{D} / \mathrm{Dt}$.................... The substantial derivative

$\mathrm{x}, \mathrm{y}$..................... The $\mathrm{x}$ and $\mathrm{y}$ Cartesian coordinates of a point

n ....................... The unit normal to a surface

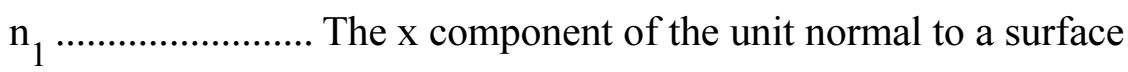

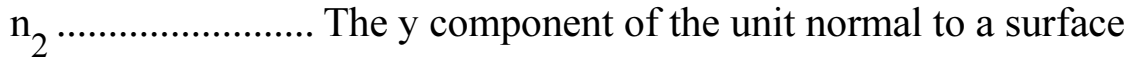

i........................ The imaginary number given by $\sqrt{ }(-1)$ or an integer depending on context

$\mathrm{z}=\mathrm{x}+\mathrm{i} \mathrm{y} \ldots \ldots \ldots \ldots . . . . .$. The complex coordinate

$\beta=\phi+\mathrm{i} \psi \ldots \ldots \ldots . .$. The complex potential

Г........................ Influence coefficient

$\mathrm{L}_{\mathrm{d}} \ldots \ldots . . . . . . . . . . . . . .$. Desingularization distance

$\pi$...................... The value for Pi $(3.141592654 \ldots)$

c ........................ The local wave velocity

P....................... Pressure

$\eta$........................ Free surface elevation

$\theta$...................... Angle varying from zero on the leading edge to $\pi$ on the trailing edge of the obstruction

$\mathrm{C}_{\mathrm{p}}=\mathrm{P} / \rho \mathrm{gh}$........... Pressure coefficient

$\mathrm{C}_{\mathrm{d}}=\mathrm{drag} / \rho \mathrm{gh}^{2} \ldots .$. Drag coefficient

$\mathrm{C}_{1}=$ lift $/ \rho \mathrm{gh}^{2} \ldots \ldots .$. Lift coefficient

PE ..................... Potential energy

KE...................... Kinetic energy 


\section{PART I Dynamic Analysis of an Inflatable Dam Subjected to a Flood}

\section{I.1 Introduction}

Inflatable dams are used in a number of water control applications. These flexible structures may be used to temporarily store water or serve as dykes. In permanent applications, they can be used to direct water in irrigation, control water level in a hydroelectric facility, or raise the height of an existing dam. Some dams have heights up to six meters and lengths up to one hundred fifty meters. They are usually constructed of a nylon reinforced polymer. Typically, they are covered with impact resistant tiles to prevent them from being punctured by gunfire and other debris.

Several thousand inflatable dams are in use today. A 640-meter long string of seven inflatable dams is in place on the Susquehanna River in Pennsylvania to create Lake Augusta. Each segment is connected by concrete pylons to create a continuous dam. Some of the flow in the Santa Ana River in California is diverted by an inflatable dam to recharge groundwater. A large project to create a 220 surface-acre ( 850 feet wide by 2 miles long) lake in Tempe Arizona using inflatable dams is currently underway. The city will construct a string of many 240 feet long inflatable dam sections ranging from six to sixteen feet in diameter. A one-inch wall thickness will be used over the entire dam. It is interesting to note that one section of the dam will be allowed to overflow at a controlled rate to produce a scenic cascade. Water will then be pumped back into to the lake to prevent runoff. The total construction cost of the dam is estimated to be forty million dollars. Many other examples of successful dams can be found worldwide. A 
few inflatable dams have failed during service. The Mangla Dam in Pakistan ${ }^{1}$ for example, became dynamically unstable and failed under overflow conditions.

Currently, inflatable dams are not used to suppress floods in emergencies. It is desired to extend their use for this purpose. This requires some research to predict the dynamic response to flood conditions. Several authors have addressed the analysis of inflatable dams. For example, Hsieh and Plaut ${ }^{2}$, and Al-Brahim ${ }^{3}$ analyzed the free vibrations of two-dimensional inflatable dams, Dakshina, Reddy and Plaut ${ }^{4}$ studied threedimensional vibrations of an inflatable dam, and Alwan ${ }^{5}$ performed modal analysis of an inflatable dam subjected to a flood. $\mathrm{Wu}$ and Plaut ${ }^{6}$ analyzed an inflatable dam under overflow conditions. In this study, a dynamic simulation of the response of an inflatable dam subjected to a flood was carried out to determine the survivability envelope of the dam where it can operate without rupture, or overflow.

The problem of a flood impinging on an inflatable dam was assumed to be twodimensional. In this study, a flood is taken to be a uniform stream of water striking the dam. The analysis begins when the front of the flood is completely in contact with the dam. The dam is anchored to the bottom at two points using pinned boundary conditions. Its stress free shape (initial shape) is that of a large semicircle. The dam has a uniform

1 Binnie, G. M., Thomas, A. R. and Gwyther, J. R., "Inflatable weir used during construction of Mangala Dam", Proc. Instn. Civ, Engs, Part I 54, 1973

${ }^{2}$ Hsieh, J. C., and Plaut, R. H., “Free vibrations of Inflatable Dams”, Acta Mech. 85, 1990.

3 Al-Brahim, A. M., "Free Vibration of Membrane Dams", European Earthquake Engineering 8, 1994.

4 Dakshina Moorthy, C. M., Reddy, J. N. \& Plaut, R. H., “Three dimensional vibrations of inflatable dams", Thin-walled Structures 21, 1995.

5

Anwar, H. O., “Inflatable Dams”, Journal of Hydraulic Div., ASCE 93, 1967.

6 Wu, P. H., and Plaut, R. H., "Analysis of the Vibrations of Inflatable Dams Under Overflow Conditions", Thin-Walled Structures Vol. 26, No. 4, 1996. 
thickness and is comprised of nylon reinforced rubber. Figure I-1 illustrates the design of a typical inflatable dam.

\section{Figure I-1: Sketch of a typical inflatable dam illustrating some basic parameters influencing dam performance ( $p d f, 116 \mathrm{~KB}$ ).}

Table 1 contains the design parameters for the dam used in this study.

\section{Table I-1: Inflatable dam properties.}

\begin{tabular}{|l|l|l|}
\hline & \multicolumn{1}{|c|}{ Property: } & \multicolumn{1}{c|}{ Value } \\
\hline & Initial radius & $4.5 \mathrm{~m}$ \\
\hline Dam design & Initial thickness & $1.27 \mathrm{~cm}$ \\
\hline & Anchoring type & Double pinned \\
\hline & Density & $100000 \mathrm{~kg} / \mathrm{sq} . \mathrm{m}$ \\
\hline Material & Poisson's ratio & 0.45 \\
\hline & Modulus of elasticity & $103.4 \mathrm{MPa}$ \\
\hline & Rupture stress & $19.65 \mathrm{MPa}$ \\
\hline
\end{tabular}

The dam is supported by an applied internal pressure ranging from a pressure of 1.0 to 5.0 meters of water. This internal pressure provides nearly all the stiffness required to repel a uniform flood applied to one side of the dam. Most modern inflatable dams are single anchored designs. Although the configuration used here is double anchored, the solution method can be readily modified to simulate many other possible designs.

The flood was assumed to start with a uniform depth of 2.0 or 3.0 meters, and a uniform velocity. The flow a sufficient distance ahead of the dam retains this initial velocity and depth. This fluid flow * problem may be described in terms of two nondimensional parameters. A depth-based Froude number is defined as $F n \equiv \frac{U_{B}}{\sqrt{g \cdot h}}$, where $\mathrm{U}_{\mathrm{B}}$ is the uniform upstream velocity, $\mathrm{h}$ is the uniform upstream depth, and $\mathrm{g}$ is the gravitational acceleration. The non-dimensional dam height is given as $\alpha \equiv \frac{R}{h}$ where $\mathrm{R}$ is the radius of the dam. Non-dimensional parameters are being used here to make the fluid solution easily compatible with the dimensional structural solution. 
This problem has two distinct parts: nonlinear free-surface flow, and elastic structural dynamics. These two problems are coupled and must be solved simultaneously. Transient, fully nonlinear computations for the fluid flow were performed using a mixed Eulerian-Lagrangian formulation. An ABAQUS finite element model was used to determine the dynamic response of the dam. A numerical towing tank with the inflatable dam on the downstream boundary and open boundary conditions on the upstream vertical boundary has been developed to simulate the fluid flow. The computer simulation "tows" the flexible dam at a steady Froude number. The fluid dynamics program determines the free-surface elevation and calculates the external pressure acting on the dam surface at each time step. This pressure is then used as an input by the ABAQUS model at each time step to determine the deformation and the velocities along the dam surface and the stresses in the dam. This information is used by the fluid dynamics program in the next time step to continue the dynamic analysis. The data for the response of the free surface is translated to a coordinate frame moving with the structure to show how the free surface develops over time.

The simulation was run over a range of Froude numbers to determine the internal pressures where the structure failed. Failure takes place when the dam either ruptures or overflows. Rupture is caused by too high an internal pressure. Overflow, on the other hand, is caused by too low an internal pressure, or too high a Froude number. Thus, a service envelope is formed where the dam can operate safely. Two envelopes were developed corresponding to uniform flood depths of 2.0 and 3.0 meters. 


\section{I.2 Two - dimensional fluid - structure interaction study}

This problem can be separated into two parts at each time step. The fluid dynamic flow will be described first, followed by the structural analysis. The last section will describe how the solutions of these problems are coupled to produce the fully dynamic simulation.

\subsubsection{Mathematical Formulation of the Fluid Flow}

The unsteady, two-dimensional potential flow of an inviscid, incompressible fluid induced by the motions of the flexible boundary, is analyzed. Under the usual assumptions of a two-dimensional, inviscid, irrotational flow, the problem may be described by a velocity potential, $\phi$, and a stream function, $\psi$. The velocity potential, $\phi$, is defined so that the fluid velocity vector is given by:

$\vec{V}=\vec{\nabla} \phi$

Instead of analyzing a uniform flow incident on the flexible structure, the interaction of an initially stationary fluid with a flexible structure moving to the left at a constant speed, $\mathrm{U}_{\mathrm{B}}$ is considered. A stationary $\mathrm{x}-\mathrm{y}$ coordinate system is used with $\mathrm{y}$ positive upwards and the $\mathrm{x}$ axis coinciding with the upper left corner of the undisturbed free surface. The coordinate frame and the fluid domain are shown in Figure I-2.

\section{Figure I-2: Numerical towing tank layout (pdf, $13 \mathrm{~KB}$ ).}

The fluid domain is bounded by the free surface, the flexible boundary surface, the bottom and the far-field upstream boundary. Since the right boundary is moving to the left, the length, $\mathrm{L}$ of the numerical towing tank reduces with time. For the numerical results presented in this study, the length of the tank was chosen equal to 40 times the fluid depth. This value of $\mathrm{L}$ was sufficient to provide the desired results before the computational domain became too short. Non-dimensional variables are chosen such that the initial fluid depth, the acceleration of gravity and the fluid density are equal to one. 
The fluid flow solution was non-dimensionalized to allow easy application of various depths. A summary of non-dimensional parameters is as follows: length variables such as the dam height or nodal coordinates are non-dimensionalized on the upstream depth (h), the pressure is non-dimensionalized by $\rho$ gh, and velocities are non-dimensionalized by $\sqrt{g h}$. In the fluid domain $\mathrm{R}$, the velocity potential $\phi$, must satisfy the Laplace equation:

$\nabla^{2} \phi=0$

On the free surface, $\mathrm{C}_{\mathrm{F}}$, the kinematic boundary conditions are:

$$
\frac{D X}{D t}=\frac{\partial \phi}{\partial x} \quad \text { and } \quad \frac{D Y}{D t}=\frac{\partial \phi}{\partial y}
$$

where $\mathrm{X}, \mathrm{Y}$ are the $\mathrm{x}$ and $\mathrm{y}$ coordinates of the particle on the free surface. The dynamic free-surface condition is given by Bernoulli's equation:

$$
\frac{D \phi}{D t}=-\eta+\frac{(\nabla \phi)^{2}}{2}
$$

where $\mathrm{D}$ is the substantial derivative, $\mathrm{x}$ and $\mathrm{y}$ are the coordinates of the position of a fluid particle, and $\eta$ is the free surface elevation. On the flexible boundary surface, $C_{S}$, the fluid flow satisfies the no-penetration condition:

$$
\frac{\partial \psi}{\partial \vec{s}}=\left(u_{d}-U_{B}\right) \hat{n}_{1}+v_{d} \hat{n}_{2}
$$

where $U_{B}$ is the velocity of the boundary, $n_{1}$ is the $x$ component of the unit normal to the surface, and $\mathrm{n}_{2}$ is the $\mathrm{y}$ component of the unit normal to the surface. $\mathrm{u}_{\mathrm{d}}$ and $\mathrm{v}_{\mathrm{d}}$ are the components of the velocity due to deformation of the boundary in the $\mathrm{x}$ and $\mathrm{y}$ directions, respectively. On the flat bottom, $\mathrm{C}_{\mathrm{B}}$ :

$$
\frac{\partial \phi}{\partial n}=0
$$


The complex coordinate is defined as $\mathrm{z}=\mathrm{x}+\mathrm{i} \mathrm{y}$, and the complex velocity potential, $\beta$, as $\beta(z)=\phi(z)+i \psi(z)$. Since $\beta$ is analytic in the fluid domain, it satisfies Cauchy's integral theorem:

$$
\oint_{C} \frac{\beta(z)}{\left(z-z_{k}\right)} d z=\left\{\begin{array}{l}
0 \text { for } z_{k} \text { outside the fluid domain } \\
-i \alpha_{k} \beta\left(z_{k}\right) \text { for } z_{k} \text { on the fluid boundary } \\
-2 \pi \mathrm{i} \beta\left(z_{k}\right) \text { for } z_{k} \text { inside the fluid domain }
\end{array}\right.
$$

where the contour $\mathrm{C}$ consists of the free surface, $\mathrm{C}_{\mathrm{F}}$, the bottom, $\mathrm{C}_{\mathrm{B}}$, the flexible boundary surface, $\mathrm{C}_{\mathrm{S}}$, and the upstream boundary. $\mathrm{z}_{\mathrm{k}}$ is an arbitrary control point. The contour $\mathrm{C}$ is traversed such that the region $\mathrm{R}$ always lies to its left and $\alpha_{\mathrm{k}}$ is the angle between two elements adjacent to $z_{k}$ on the contour. For a smooth contour $\alpha_{k}=-\pi$. To solve the boundary value problem for the unknown complex potential, $\beta(\mathrm{z})$, the control points were placed a small distance outside the fluid domain and equation (6a) was used. The $\mathrm{j}^{\text {th }}$ control point is placed a distance $\mathrm{L}_{\mathrm{d}}$ from the $\mathrm{j}^{\text {th }}$ node along the outward unit normal to the panel formed by the $j$ and $j+1$ nodes. $L_{d}$ is determined as a small portion of the panel length to avoid problems related to ill conditioning(see Schultz and $\mathrm{Hong}^{7}$ ):

$$
L_{d}=1 \times 10^{-12}\left|z_{j+1}-z_{j}\right|
$$

A mixed Eulerian-Lagrangian formulation is employed to solve the boundary value problem (1)-(5). At each time step, the integral equation (6a) is solved for the unknown values of the complex potential (Eulerian part). Once the velocity potential is known, the free surface conditions (2) and (3) are used to update the positions and the values of the velocity potential of particles of fixed identity (Lagrangian part). This method has been used very successfully to predict a variety of nonlinear wave

7 Schultz, W. W., and Hong, S. W., "Solution of Potential Problems Using an Over Determined Complex Boundary Integral Method", Journal of Computational Physics 84, 1989. 
phenomena by a number of investigators (Longuet-Higgins and $\operatorname{Cokelet}^{8}$, Vinje and Brevig $^{9}$, Lin et al. ${ }^{10}$, Cointe ${ }^{11}$, Muthedath ${ }^{12}$ ).

\section{I.2.2 Numerical implementation}

The boundary $\mathrm{C}$ is divided into elements (panels). Figure I-2 shows the layout of the tank and boundary elements. A total of 509 nodes were used for the simulations presented here. 300 nodes were used on the free surface, 6 were used on the upstream boundary, 201 were used on the bottom boundary and 6 were used on the surface of the structure. This created 299, 5, 200, and 5 panels on the free surface, upstream boundary, bottom boundary, and structure surface, respectively. The nodes were spaced to provide uniform panel lengths on the computational boundary. Note that the panel lengths are not necessarily equal on the boundary segments. This node distribution, along with the tank length of 40 times the upstream depth were chosen by trial and error as the best compromise between numerical accuracy and computer running time.

The flexible obstruction making up the right hand boundary is translated towards the left end of the tank to simulate flood conditions. Nodes on the free surface and the bottom boundary were redistributed at each time step to retain equal panel lengths on

8 Longuet-Higgins, M. S., and Cokelet, E. D., "The deformation of steep surface waves on water", Proc. R. Soc. Lond. A. 350, 1-26, 1976.

9 Vinje, T. and Brevig, P., "Breaking waves on finite water depths. A numerical study.", The ship research institute of Norway, 1981.

10 Lin, W., "Nonlinear motion of the free surface near a moving body", Ph.D. Thesis, Massachusetts Institute of Technology, Cambridge, Mass., 1984.

11 Cointe, R. "Nonlinear simulation of transient free surface flows", Proceedings of the fifth international conference on numerical ship hydrodynamics, Hiroshima, Japan, pp. 239-250, 1989.

12 Muthedath, P., "Numerical study of nonlinear free surface flows", M.S. Thesis, Virginia Polytechnic Institute and State University, Blacksburg, VA, 1992. 
these boundaries as the tank length decreased. This is accurate as long as the time step used to update the position of the free surface is very small. In the limit as the time step is decreased towards zero, this gives an exact result. A time step of 0.022576 seconds gives results that do not perceptively improve with even smaller time steps. This value was also obtained by trial and error with the computer simulation.

Within each panel, the complex potential, $\beta(z)$, is assumed to vary linearly with $z$. This can be expressed as:

$$
\beta(z)=\frac{z-z_{j}}{z_{j-1}-z_{j}} \beta_{j-1}+\frac{z-z_{j-1}}{z_{j}-z_{j-1}} \beta_{j}
$$

This approximation of $\beta(\mathrm{z})$ reduces the problem of finding a continuous potential to determining the unknown nodal values $\beta_{\mathrm{j}}$. These are found by collocation, that is, by satisfying the integral equation (6) at the panel vertices. The result is a set of linear equations that can be solved for the unknown $\beta_{\mathrm{j}}^{\mathrm{s}}$. If equation (7) is substituted into equation (6a), a discretized form of the integral equation is found:

$$
\oint_{C} \frac{\beta(z)}{\left(z-z_{k}\right)} d z=\sum_{j=1}^{N} \Gamma_{k, j} \beta_{j}=0
$$

where the influence coefficients are given by :

$$
\Gamma_{k, j}=\left\{\frac{z_{k}-z_{j-1}}{z_{j}-z_{j-1}}\right\} \ln \left\{\frac{z_{j}-z_{k}}{z_{j-1}-z_{k}}\right\}+\left\{\frac{z_{k}-z_{j+1}}{z_{j}-z_{j+1}}\right\} \ln \left\{\frac{z_{j+1}-z_{k}}{z_{j}-z_{k}}\right\}
$$

$\mathrm{z}_{\mathrm{j}}$ and $\mathrm{z}_{\mathrm{k}}$ are the nodal and control point locations, respectively.

The fluid boundary consists of portions where $\phi$ is known $\left(\mathrm{C}_{\phi}\right.$ boundary $)$ and portions where $\psi$ is known $\left(\mathrm{C}_{\psi}\right.$ boundary). At the free surface, the velocity potential $\phi$ is known $\left(\mathrm{C}_{\phi}\right.$ boundary $)$ while on the bottom, the upstream boundary, and the flexible surface of the structure the stream function $\psi$ is known $\left(\mathrm{C}_{\psi}\right.$ boundary). The application of the boundary conditions is done by setting the appropriate terms in equation (9) to zero as follows: 
$\operatorname{Re}\left\{\sum_{j=1}^{N} \Gamma_{k, j} \beta_{j}\right\}=0 \quad$ for $\mathrm{z}_{\mathrm{k}}$ on or close to $\mathrm{C}_{\phi}$

$\operatorname{Re}\left\{i \sum_{j=1}^{N} \Gamma_{k, j} \beta_{j}\right\}=0 \quad$ for $\mathrm{z}_{\mathrm{k}}$ on or close to $\mathrm{C}_{\psi}$

Special attention to the nodes at the intersection of the free surface with the upstream boundary and the surface of the structure is required. At these points, $\phi$ and $\psi$ are completely known. No equation in (9) corresponding to $\phi$ or $\psi$ on that point is required and is not used. This is known to be an effective treatment $\left(\operatorname{see}^{1} \operatorname{lin}^{10}\right)$.

Time stepping of equations (2) and (3) to determine the position of the free surface, is performed by Hamming's fourth order predictor/corrector method to determine the location of the free surface nodes. A Runge- Kutta fourth order method is employed for the first four time steps to provide the initial starting data for use with Hamming's method. The spatial derivatives in these equations are determined by central difference schemes. Equation (6a) is solved using intermediate free surface positions and the velocities of the free surface are calculated as required to produce function evaluations for the numerical integration methods.

Muthedath ${ }^{12}$ developed a FORTRAN computer code that used the aforementioned procedure to analyze highly nonlinear free surface flows such as an impulse wave maker and a wedge entry problem. He validated the numerical results form the computer code through a comparison with known analytical results. His computer code was modified to solve the inflatable dam problem presented here. Three main changes were made: a smoothing formula for the free surface particles was added, an upstream open boundary condition was used to prevent any reflections form the upstream boundary, and the pressure acting on the dam calculated using Bernoulli's equation was added. These modifications are detailed in the next sections. Extensive computer procedure were also added to allow the fluids code to interact dynamically with the ABAQUS structural model. This interaction will be described in section I.2.3.1. 


\section{I.2.2.1 Smoothing and node distribution on the free surface}

Nodes on the free surface and the bottom boundary were redistributed at each time step to retain equal panel lengths on these boundaries as the tank length decreased. This is accurate as long as the time step used to update the position of the free surface is very small. In the limit as the time step is decreased towards zero, this gives an exact result. A time step of 0.022576 seconds gives results that do not perceptively improve with even smaller time steps.

Nodes on the free surface are smoothed every five time steps using a fifth order smoothing formula developed by Longuet-Higgins and Cokelet ${ }^{8}$ :

$\bar{y}_{i}=\frac{1}{16}\left(-y_{i-2}+4 y_{i-1}+10 y_{i}+4 y_{i+1}-y_{i+2}\right)$

where the subscript $\mathrm{i}$ indicates the $\mathrm{i}^{\text {th }}$ node, $\mathrm{i}-1$ is the previous node and so forth. This formula worked very well and suppressed all saw-tooth instability seen in this study. Note: the two beginning and ending nodes are not smoothed.

\section{I.2.2.2 Upstream boundary condition}

A satisfactory treatment of the upstream boundary is of fundamental importance to the success of the numerical simulations. In this work, Sommerfeld radiation conditions are imposed at the upstream boundary in a manner similar to what has been

used in other problems (Orlanski ${ }^{13}$ ). The following condition is imposed to simulate open boundary conditions:

$\frac{\partial \psi}{\partial t}+c \frac{\partial \psi}{\partial x}=0$

13 Orlanski, I. "A simple boundary condition for unbounded hyperbolic flows", Journal of Computational Physics, Vol. 21, pp. 251-269, 1976. 
where $\mathrm{c}$ is the local wave velocity. This condition makes the upstream boundary transparent to all waves of velocity c, thus eliminating reflections. The local wave velocity, $\mathrm{c}$ is in the general case unknown. Some authors (Han, Meng and Innis ${ }^{14}$ ) suggested a numerical method of calculating $\mathrm{c}$. In the present study, $\mathrm{c}$ is set equal to the phase velocity $\sqrt{g h}=1$ (unit depth and gravitational acceleration have been assumed). The numerical method used to apply equation (13) involves adding a column of points just inside the upstream and downstream boundaries. Then a finite difference scheme is employed to find the spatial and temporal derivatives of $\psi(\mathrm{z})$. For the time derivative, a backward difference scheme was used. For the spatial derivative, a forward difference scheme was used. This gives:

$\frac{\psi\left(x_{u}, y_{u}, t\right)-\psi\left(x_{u}, y_{u}, t-\Delta t\right)}{\Delta t}+c \frac{\psi\left(x_{u}+\Delta x, y_{u}, t-\Delta t\right)-\psi\left(x_{u}, y_{u}, t-\Delta t\right)}{\Delta x}=0$

Rearranging to determine the nodal value of $\psi\left(x_{u}, y_{u}, t\right)$,

$\psi\left(x_{u}, y_{u}, t\right)=\psi\left(x_{u}, y_{u}, t-\Delta t\right)-c \frac{\Delta t}{\Delta x}\left[\psi\left(x_{u}+\Delta x, y_{u}, t-\Delta t\right)-\psi\left(x_{u}, y_{u}, t-\Delta t\right)\right]$

where $x_{u}, y_{u}$ is the coordinate of a node on the upstream boundary $\left(x_{u}=0\right), t$ is the current time in the simulation, $\Delta \mathrm{t}$ is the time step interval, and $\Delta \mathrm{x}$ is the distance of the additional points from the upstream boundary. The value of $\Delta \mathrm{x}$ used was 5 times the upstream depth. As usual, this optimum value for $\Delta \mathrm{x}$ was determined by trial and error. This scheme was tested, using both first and second order difference schemes to approximate the derivatives of $\psi(\mathrm{z})$, and various ways to determine the propagation velocity, c. The method shown and the simple choice of $\mathrm{c}=1$ was found to be superior and reduces the reflected waves to a minimum.

14 Han, T.Y., Meng, J. C. S., and Innis, G. E., "An open boundary condition for incompressible stratified flows”, Journal of Computational Physics, Vol. 49, 276-297, 1983. 
At each time step $(\mathrm{t}-\Delta \mathrm{t})$ after solving for the value of $\psi$ on the boundary nodes, the value of $\psi$ on the interior points, $\psi\left(\mathrm{x}_{\mathrm{u}}+\Delta \mathrm{x}, \mathrm{y}_{\mathrm{u}}, \mathrm{t}-\Delta \mathrm{t}\right)$ is determined using equation (6c). Then equation (15) is used to update the value of $\psi\left(\mathrm{x}_{\mathrm{u}}, \mathrm{y}_{\mathrm{u}}, \mathrm{t}\right)$ at the nodes making up the upstream boundary at each time step. Although this open boundary condition introduces some slight disturbances in the free surface close to the boundary, it does prevent any significant reflections from affecting the results.

\section{I.2.2.3 Calculation of the pressure acting on the dam}

The pressure over the surface of the structure is found using Bernoulli's equation:

$P=\left[-\frac{\partial \varphi}{\partial t}-\frac{(\nabla \phi)^{2}}{2}-(y-\eta)\right] \rho g h$

where $\rho$ is the density of water $\left(1000 \mathrm{Kg} / \mathrm{m}^{3}\right), \mathrm{g}$ is the gravitational acceleration $(9.81$

$\left.\mathrm{m} / \mathrm{s}^{2}\right)$, and $\mathrm{h}$ is the upstream depth $(2$ or $3 \mathrm{~m})$. In order to evaluate the time derivative of the velocity potential, $\varphi_{\mathrm{t}}$, observe that the time derivative of the complex velocity potential, $\beta_{\mathrm{t}}$, is analytic in the fluid domain. Therefore, at each time step, the same numerical procedure that was used to determine $\beta$ is repeated to evaluate $\beta_{t}$. Recall $\varphi_{t}$ is the real part of $\beta_{\mathrm{t}}$.

\section{I.2.3 Structural Analysis}

An ABAQUS finite element model was used to determine the structural response of the flexible dam. The model is comprised of one hundred S4R type thin shell elements arranged in a 4.5 meter radius semicircular arc with a breadth of unity. The elements have a uniform thickness of $1.27 \mathrm{~cm}$ and uniform material properties given in Table 1 . The circumferential free edges were restrained by enforcing symmetry in the $\mathrm{z}$ direction. This means that these edges were not allowed to rotate along the $\mathrm{x}$ or $\mathrm{y}$ axes and not 
allowed to translate in the $\mathrm{z}$ direction. The transverse edges were anchored to the bottom using pinned boundary conditions. A uniform pressure was applied to the inside face of each element. The compressibility of the internal air was taken into account by assuming that it behaves isothermally. Hence, the internal pressure is not constant. The isothermal constant was determined by taking the product of the initial prescribed pressure and the static volume of the dam. Then the base value for the internal pressure at any point during the simulation may be found by dividing this constant by the new volume of the dam. The pressure caused by the effects of the external fluid (flood) is subtracted from the internal base pressure to obtain the pressure "felt" by the dam material. This pressure was distributed appropriately over elements making up the dam in the ABAQUS model. Appendix A contains a sample printout of the ABAQUS finite element model.

\section{I.2.3.1 Fluid - structure interaction}

Figure I-3 contains a flow chart of the fluid structure interaction problem.

\section{Figure I-3: Flow chart of the solution method for the no-overflow case (pdf, $15 \mathrm{~KB}$ ).}

Values for the structural properties of the dam material, initial dam shape, the initial (base) internal dam pressure, the flood Froude number and the initial flood depth are input into a preprocessor. The preprocessor takes these values and creates the ABAQUS finite element model. Since the dam is initially started from rest, a static analysis must be performed first to determine the static shape of the dam produced by the influence of the external hydrostatic pressure and the internal inflation pressure. The hydrostatic pressure is found directly from the formula: $\mathrm{P}_{\text {stat }}=\rho \mathrm{g} \mathrm{d}_{\text {ave }}$, where $\rho$ is the density of water $(1000$ $\left.\mathrm{Kg} / \mathrm{m}^{3}\right)$, $\mathrm{g}$ is the gravitational acceleration $\left(9.81 \mathrm{~m} / \mathrm{s}^{2}\right)$, and $\mathrm{d}_{\text {ave }}$ is the average depth of each submerged element in the ABAQUS model. Figure I-4 illustrates the application of the pressures on the structural model.

Figure I-4: Solving the fluid structure interaction problem (pdf, $19 \mathrm{~KB}$ ). Appendix A contains a sample printout of an ABAQUS static analysis model used to find the static shape of the dam. The total pressure acting on each element is found by 
subtracting the static pressure, $\mathrm{P}_{\text {stat }}$, from the internal pressure, $\mathrm{P}_{\text {int }}$. During the dynamic steps the total pressure is found by subtracting the external pressure, $\mathrm{P}_{\mathrm{dyn}}$ found by the fluids code from the isothermal internal pressure, $\mathrm{P}_{\text {iso }}$ described above.

Once the static shape of the dam is found, the dynamic simulation is started. The dam is started from rest to the final Froude number desired for each run. For high Froude number runs the dam velocity was incrementally increased by 0.1 to the final value over several time steps to prevent a large jet of water from forming at the dam surface. During each time step the following sub-steps are performed. The fluids code is run to determine the change in the free surface shape, and the new pressure distribution acting on the dam. The total pressure is calculated as $\mathrm{P}_{\text {tot }}=\mathrm{P}_{\text {iso }}-\mathrm{P}_{\text {dyn }}$, and is used to create an ABAQUS restart file to perform a dynamic analysis over one time step. A sample restart file is located in appendix B. The ABAQUS dynamic analysis produces the new dam shape, the velocity distribution for the next time step and the stresses in the dam material. Finally, the velocity distribution is integrated along the dam surface to find the nodal values of the stream function $\psi$, and the whole procedure is repeated for the next time step. Since the fluids program uses non-dimensional values, the ABAQUS results for the velocity must be divided by $\sqrt{g h}$ prior to integration. Integration to find the nodal values of $\psi$, were obtained using Newton's method:

$\psi_{i+1}=\psi_{i}+\frac{\left(\frac{V_{i+1}}{\sqrt{g h}}-\frac{V_{i}}{\sqrt{g h}}\right)}{\sqrt{\left(x_{i+1}-x_{i}\right)^{2}+\left(y_{i+1}-y_{i}\right)^{2}}}$

where $\mathrm{i}$ goes form the first node on the bottom corner of the flexible boundary to the node just below the one contacting the free surface (the next node is the contacting node on the free surface). $\psi$ on the intersection of the bottom and the flexible boundary is zero due to the no penetration condition on the bottom. Since the flexible boundary and the ABAQUS model have different node spacing, the values of $\mathrm{V}_{\mathrm{i}}$ were found by linear interpolation between the values at adjacent nodes on the ABAQUS model. The 
displacements given by the structural solution were non-dimensionalized by dividing by the upstream depth and interpolated to produce the correct nodal values for the fluid flow model in a similar fashion.

\section{I.2.3.2 Failure criterion}

Failure may occur in one of two ways, overflow and rupture. Overflow defeats the purpose of the dam. This failure mode is commonly referred to in structural design as failure due to excessive deformation. Rupture occurs when the breaking stress for the dam material is reached. The critical stress used here is $19.65 \mathrm{MPa}$. This stress is approximated by using a simple rule of mixtures to a rubber and nylon laminate ( $86 \%$ rubber, $14 \%$ nylon) typically used in the construction of inflatable dams.

\section{I.2.3.3 Determination of the failure envelope}

Failure is governed by three parameters: the internal dam pressure the flood depth and the flow Froude number. Two flood depths were chosen for this study, 2.0 and 3.0 meters. A serviceability envelope was produced for each depth. This envelope is the region of the internal pressure versus flood Froude number where the inflatable dam does not fail due to either overflow or rupture. A similar envelope could be developed for internal pressure versus flood depth, but was not done in this study.

The upper limit of the failure envelope corresponding to the internal pressure when the dam ruptures under hydrostatic pressures was found by iteratively running the static finite element model. Different values for the internal pressure were used until two values were obtained, one on each side of the rupture line, which only had a two percent difference. The lower limit of the failure envelope where the dam just overflows was found by running the full fluid structure interaction model in similar fashion as before while the Froude number was held at a fixed value. When the internal pressure required to suppress the flood exceeded the rupture value, the maximum flood Froude number sustainable had been reached, and the failure envelope was completely defined. 


\section{I.2.3.4 Applicability of the Results}

The results presented here are applicable to a two-dimensional flow. This is a good approximation if the dam wide enough to minimize the effects from the ends of the dam and if there is little cross flow present. In addition, the fluid flow solution requires that the flow be irrotational. No surface friction or internal structural damping has been taken into account. This is a good approximation as long as the velocities of the dam and the fluid do not become large. 


\section{I.3 Numerical Results}

\section{I.3.1 Fluid Response}

Figure I-5 shows a sample displacement profile for a typical run in which the dam does not fail in overflow or rupture.

Figure I-5: Sample displacement profile for an inflatable dam in a flood (JPEG, 234 KB).

As an alternative representation, Figure I-6 depicts the motion in a profile-temporal plot.

Figure I-6: Sample displacement - time profile plot of the free surface and an inflatable dam (pdf, $70 \mathrm{~KB})$.

As seen in the figure, the dam oscillates back and forth, as a bore of water is rejected. Further oscillation causes small waves to occur on top of the bore right next to the dam. As time progresses, the water height in front of the dam reaches a steady value. This height depends on the depth based Froude number of the flood. The primary contribution to the forces the dam feels due to the flood is from the hydrostatic pressure increase due to this increase in water level immediately in front of the dam.

Figure I-7 is a sample free surface profile for a tall rigid dam illustrating the formation of a jet of water where the free surface contacts the dam.

\section{Figure I-7: Plot of the free surface response for a tall rigid dam (pdf, $27 \mathrm{~KB}$ ).}

There is a jet of water produced when the flood first strikes the dam in the rigid case but not the flexible case. A jet is predicted at such singularities in the potential flow field by Hughes ${ }^{15}$. The jet does not form in the case of a flexible dam since the structure deforms away from the jet and in a sense damps it out.

15 Hughes, O. F., "Some characteristics in the free surface in the wedge entry problem", Journal of Engineering Mathematics, No. 4, 367-375, 1973. 


\section{I.3.2 Structural Response}

\section{I.3.2.1 Motion of the dam}

Figures 5 and 6 also show the motion of a dam for no overflow. As seen in the figure, the dam is pushed away from the flood and oscillates. The dam height is effectively reduced from being pushed over. The magnitude of the oscillations depends primarily on the internal pressure. As the internal pressure is increased, the oscillations decrease in magnitude, until they are hardly seen at all. At this point, the response of the flood closely resembles the results for the case of a rigid dam. A low pressure reduces the dam's ability to suppress the flood. When the internal pressure is brought below a certain value, the dam can no longer hold back the flood, and overflow occurs. Figure I-8 is a sample plot of an inflatable dam starting to overflow.

Figure I-8: Sample displacement profile for an inflatable dam during overflow (JPEG, $166 \mathrm{~KB})$.

Overflow is seen in this study as the point where the thin region of water over the dam collapses. When this occurs, the nodes on the free surface and the dam touch and break down the numerical computations. The overflow pressure found here will be conservative as the dam may actually be barely able to contain the flood after the numerical computations break down.

Figure I-9 is a plot of the trace of several nodes on the surface of the dam during a typical run.

Figure I-9: Trace of several nodes on the surface of an oscillating inflatable dam (pdf, 20 $\underline{K B})$.

The node on the upstream side of the dam, at about the initial water level, displaces down and away from the flood, then returns on nearly the same path. The node on the top of the dam follows an orbital path such that it does not retrace its path as it "bounces back". The node on the downstream side of the dam displaces forward and backward on about the same path. Figure I-10 is a plot of the motion of the top node as a function of time. 
Figure I-10: The motion of the uppermost node of an oscillating inflatable dam as a function of time (pdf, $21 \mathrm{~KB}$ ).

As seen in the plot, the motion in the $\mathrm{x}$ direction appears to be almost sinusoidal. For a flood depth of two meters, flood Froude number of 0.3, and an internal pressure of two meters of water, the period of this motion is roughly constant at about 0.377 seconds. The motion in the y direction is not as uniform. This shows that there is more than one mode being excited. The amplitude of the motion of a point on the dam is damped out during the run due to wave generation on the free surface.

\section{I.3.2.2 Stress in the dam}

Figure I-11 is a plot of the static stress (upstream flood speed $=0$ ) in the dam for a low inflation pressure.

Figure 1-11: Plot of the static stress in the dam for a low inflation pressure (pdf, $4 \mathrm{~KB}$ ).

The tensile stress is roughly constant over the surface of the dam. For an internal pressure of 1.75 meters of water, and a water depth of 3.0 meters the mean circumferential stress is $75 \mathrm{KPa}$. The mean transverse stress is $35 \mathrm{KPa}$. The maximum stress due to bending occurs about one meter from the bottom on the flood side of the dam. For this case, the maximum stress due to a combined state of bending and tension is about $340 \mathrm{KPa}$. For low pressures the bending stress is significant. Figure I-12 is a plot of the static stresses in the dam for the rupture pressure in a 3.0 meter deep flood.

Figure I-12: Plot of the static stresses in the dam for an inflation pressure that would cause the dam to rupture ( $p d f, 3 \mathrm{~KB}$ ).

For high pressures, closer to the rupture pressure, the bending stress is insignificant. For an internal pressure of 4.85 meters of water (the rupture pressure for this depth) and a water depth of 3.0 meters, the mean circumferential stress roughly equals the maximum stress (through the thickness). The mean circumferential stress is $19.5 \mathrm{MPa}$, and the mean transverse stress is $8.82 \mathrm{MPa}$. 
Figure I-13 contains sample results for the stress fluctuation with time at a node on the top of the dam.

Figure I-13: Dynamic stresses at a point on the top of the dam (pdf, $23 \mathrm{~KB}$ ).

The stresses at other locations in the dam are qualitatively similar to the sample shown in Figure I-13. As seen in the figure, the highest stress occurs near the beginning of the run, and that the dynamic stress fluctuation is only about $10 \%$ of the total stress. Therefore, if the dam is going to rupture, it will most likely occur during the beginning of the simulation under static loading. As the simulation progresses, there is a drop in the mean stress. This is due to the increasing depth in front of the dam. The increasing hydrostatic pressure outside the dam partially counteracts the pressure inside the dam. This results in decreased stresses in the dam. This is an interesting result because the flood actually lowers the stresses in the dam material.

\section{I.3.3 The Operational Envelope}

Figures I-15 and I-16 are plots of the serviceability regions for flood depths of two and three meters, respectively.

Figure I-14: Serviceability envelope for a flood depth of two meters (pdf, $10 \mathrm{~KB})$. Figure 1-15: Serviceability envelope for a flood depth of three meters (pdf, $10 \mathrm{~KB}$ ).

A comparison of these two plots reveals that for a lower flood depth, a faster moving flood can be suppressed. In addition, the rupture pressure for a lower flood depth is actually lower than that for a higher flood. This is due to the partial cancellation of external and internal pressures. A higher depth counteracts more of the applied internal pressure, and actually stabilizes the dam against rupture. 


\section{I.4 Suggestions for Future Work}

Unlike the double-anchored design, most modern inflatable dams have a single lengthwise anchor. The solution method developed here could be repeated for these and other dam cross-sections. Furthermore, the effects of varying the thickness, strength and elasticity could be investigated using this method.

Some inflatable dams have failed due to V-notch instability. This failure mode is characterized by a mid-span V shaped depression through which water can spill over the dam rapidly. A three-dimensional analysis is required to predict V-notch instability. This analysis could also take into consideration the anchoring of the transverse ends to the flood banks. An inflatable dam may also fail due to impact from a partially submerged object such as a tree trunk or log. A three-dimensional analysis could be performed to examine the tolerance to an impacting object. 


\section{I.5 Conclusions}

The dynamic, nonlinear response of an inflatable dam was studied for a range of flood depths and flood speeds. The driving factor in the adequacy of an inflatable dam is the internal pressure. If this pressure is too low, the water will overflow the dam. If it is too high, the dam will rupture. A serviceability envelope is formed between the rupture pressure and the overflow pressure where the dam is successful at suppressing a flood. Two flood depths were studied, two and three meters. A serviceability envelope was produced for both cases. 


\section{PART II Free Surface Flow Over A Semi- Circular Obstruction}

\section{II.1 Introduction}

The fully nonlinear, free-surface, two-dimensional potential flow of an incompressible fluid over a semi-circular bottom obstruction, is analyzed here. The flow a sufficient distance ahead of the obstruction has a uniform velocity and depth. This problem may be described in terms of two non-dimensional parameters. A depth-based Froude number is defined as $F n \equiv \frac{U_{B}}{\sqrt{g \cdot h}}$, where $U_{B}$ is the uniform upstream velocity, $\mathrm{h}$ is the uniform upstream depth, and $g$ is the gravitational acceleration. The nondimensional obstruction height is given as $\alpha \equiv \frac{R}{h}$ where $\mathrm{R}$ is the radius of the obstacle. The steady flow over an obstacle has been studied by a number of investigators (e.g., Forbes $^{16}$, Forbes and Schwartz ${ }^{17}$, Zhang and $\mathrm{Zhu}^{18}$, Vanden-Broeck ${ }^{19}$, Houghton and Kasahara $^{20}$ and Lawrence ${ }^{21}$ ). The steady-state response of the free surface can be

16 Forbes, L. K., “Critical free-surface flow over a semi-circular obstruction”, Journal of Engineering Mathematics, Vol. 22, pp. 3-13, 1988.

17 Forbes, L. K., and Schwartz, L. W., "Free-surface flow over a semicircular obstruction", Journal of Fluid Mechanics, Vol. 114, pp. 299-314, 1982.

18 Zhang, Y. and Zhu, S., "Open channel flow past a bottom obstruction", Journal of Engineering Mathematics, Vol. 30, pp. 487-499, 1996.

19 Vanden-Broeck, J. M., "Free-surface flow over an obstruction in a channel", Physics of Fluids, Vol. 30, pp. $2315-2317,1987$.

20 Houghton, D. D. and Kasahara, A., "Nonlinear shallow fluid flow over an isolated ridge" Communications on pure and applied mathematics, Vol. 21, pp. 1-23, 1968. 
classified into certain flow regimes depending on the upstream depth based Froude number and the non-dimensional obstruction height. These regimes have common free surface characteristics, and are depicted in Figure II-1.

\section{Figure II-1: The steady state flow regimes (pdf, $45 \mathrm{~KB}$ ).}

Five distinct patterns for the free surface behavior at steady state have been identified. These are: subcritical, supercritical, partially blocked with no lee (downstream) hydraulic jump, partially blocked with a lee hydraulic jump, and complete blocking. Equations defining the boundaries between the various flow regimes have been developed by Houghton and Kawahara ${ }^{20}$ and Lawrence ${ }^{21}$. In a recent study, Zhu and Zhang ${ }^{22}$ formulated the same problem in the time domain. However, mainly due to the absence of open boundary conditions, they were able to obtain numerical results only for values of the Froude number greater than one.

While the steady models have been useful in identifying some key features of the fluid problem, for certain speeds, even though the conditions are steady, the flow never reaches a steady state. This is related to the generation of unsteady solitary waves propagating upstream of the obstacle. This phenomenon occurs for a number of disturbances in a uniform flow such as a free-surface pressure distribution or a ship and has been identified by a number of authors. While Thews and Landweber ${ }^{23}$ are credited with first mentioning this phenomenon, systematic studies of this phenomenon are much

21 Lawrence, G. A., 1987, "Steady flow over an obstacle", Journal of Hydraulic Engineering, Vol. 113, No. 8, August 1987.

22 Zhu, S. and Zhang, Y., "On nonlinear transient free-surface flows over a bottom obstruction", Unpublished manuscript submitted to Physics of Fluids, 1996.

23 Thews, J. G. and Landweber, L., "The influence of shallow water on the resistance of a cruiser model", U.S. Experimental model basin, Navy Yard, Washington D.C., Rep. No. 408, pp. 31, 1935. 
more recent. $\mathrm{Wu}$ and $\mathrm{Wu}^{24}$ used a generalized Boussinesq model for long waves generated by a moving pressure or bottom obstacle. The same phenomenon was studied using the Korteweg-de Vries equation by Akylas $^{25}$, Cole $^{26}$ and $\mathrm{Mei}^{27}$. Ertekin et al. ${ }^{28}$ reported analytical results using the Green-Naghdi theory as well as experimental results. In a recent study, $\mathrm{Cao}$ et al. ${ }^{29}$ presented numerical computations of two-dimensional solitary waves generated by moving disturbances using a desingularized boundary integral method.

In this paper, the free-surface flow over a bottom obstruction is studied numerically. Unlike the previous studies, the problem is solved in the time domain. Transient, fully nonlinear computations were performed using a mixed EulerianLagrangian formulation. Unlike the Boussinesq or the $\mathrm{KdV}$ formulations which are restricted to cases where the velocity varies slowly with the depth, the present numerical computations can handle arbitrary velocity variations with depth. A numerical towing tank with open boundary conditions on the upstream and downstream vertical boundaries has been developed to perform this study. The computer simulation "tows" the semicircular bottom obstruction from rest to a steady Froude number. The program

\footnotetext{
24 Wu, D.-M. and Wu, T. Y. "Three dimensional nonlinear long waves due to moving surface pressure", Proceedings of the fourteenth symposium of naval hydrodynamics, Ann Arbor, Mich., pp. 103-129, 1982.

25 Akylas, T. R., "On the excitation of long nonlinear water waves by a moving pressure distribution", Journal of Fluid Mechanics, Vol. 141, pp. 455-466, 1984.

${ }^{26}$ Cole, S. L., “Transient waves produced by flow past a bump", Wave motion, Vol. 7, pp. 579-587, 1985.

27 Mei, C. C. "Radiation of solitons by slender bodies advancing in a shallow channel", Journal of Fluid Mechanics, Vol. 162, pp. 53-67, 1986.

28 Ertekin, R. C., Webster, W. C., and Wehausen, J. V., "Waves caused by a moving disturbance in a shallow channel of finite width", Journal of Fluid Mechanics, Vol. 169, pp. 275-292, 1986.

29 Cao, Y., Beck, R. F., and Schultz,W.W., "Numerical computations of two-dimensional solitary waves generated by moving disturbances", International Journal for Numerical Methods in Fluids, Vol. 17, pp. 905-920, 1993.
} 
determines the free-surface elevation, calculates the force coefficients, and determines the energy in the tank at each time step. The data for the response of the free surface is translated to a coordinate frame moving with the structure to show how the free surface develops over time. In addition to computing the upstream solitary waves, which confirm the findings of the approximate theories, this procedure allows the simulation of wave breaking.

A parametric study was performed for a range of values of the Froude number up to 2.5 and non-dimensional obstacle heights $\alpha$ up to 0.9 . Non-dimensional values for all parameters were used to generalize the results as much as possible. The non-dimensional parameters are defined in the Table of Symbols at the beginning of this report and when they are first presented. The boundary line separating the breaking and non-breaking wave regimes was obtained. When wave breaking does not occur, three distinct flow regimes were identified: subcritical, transcritical and supercritical. When breaking occurs it may be of any type: spilling, plunging or surging. In addition, for a range of values of the Froude number close to one, the upstream solitary waves break. A systematic study was undertaken to define the boundaries of each type of breaking and non-breaking patern. In addition, the time histories of the drag and lift coefficients as well as the freesurface elevation were obtained. Several features of the fluid flow were very different than what was predicted by the steady flow models. To the author's knowledge, while there have been quite a few steady-state studies of this problem, this is the first complete study of this problem in the time domain. 


\section{II.2 Two - dimensional fluid flow parametric study}

\section{II.2.1 Mathematical Formulation}

The unsteady, two-dimensional potential flow of an inviscid, incompressible fluid induced by a bottom obstacle moving at a constant speed $U_{B}$ along the fluid bottom is analyzed. Figure II-2 is a sketch of the numerical towing tank layout.

\section{Figure II-2: Numerical towing tank layout (pdf, $19 \mathrm{~KB})$.}

The mathematical formulation for the numerical towing tank was adopted from that used for the fluid flow solution of the previous inflatable dam problem. The flexible surface of the structure was replaced by a stationary vertical wall. The tank length remains fixed throughout the towing tank simulation. Open boundary conditions were applied to this upstream wall in a similar fashion as for the upstream boundary described in section I.2.2.2. The disturbance velocity at the downstream boundary is taken to be -1 for waves moving from left to right.

The overall solution method caries with it several basic assumptions. The fluid flow must be inviscid, and irrotational. This is accurate for slow moving, laminar flows where the action of friction on all surfaces and in the fluid itself can be neglected. The fluid must also be incompressible. Water satisfies this restriction almost perfectly. A major benefit that this simulation has over other potential flow methods is that the free surface is fully nonlinear. This feature is required to accurately show the formation of breaking waves and to accurately determine the forces acting on the structure.

A moving bottom obstruction was introduced into the tank bottom. The obstruction has an arbitrary cross section given by specifying the nodal coordinates of points making up the surface. After startup, this obstruction is "towed" along the bottom of the tank from right to left with a constant speed. On the obstruction boundary surface, $\mathrm{C}_{\mathrm{o}}$, the fluid flow satisfies the no-penetration condition: 
$\frac{\partial \psi}{\partial \vec{s}}=\left(U_{B}\right) \hat{n}_{1}$

where $U_{B}$ is the velocity of the boundary, and $n_{1}$ is the $x$ component of the unit normal to the surface. As before, on the flat bottom $\mathrm{C}_{\mathrm{B}}$ :

$$
\frac{\partial \phi}{\partial n}=0
$$

\section{II.2.1.1}

\section{Motion of the obstacle}

In the towing tank simulator the obstacle is always towed towards the left, in the negative $\mathrm{x}$ direction. The structure is started from rest with a velocity ramp. During this acceleration phase, the velocity is gradually increased in a linear fashion to its final value. A large impulsive leads to numerical instability during the start up. To prevent this, the structure was accelerated at 0.05 Fn per time step for each run.

Careful inspection of the results for the free surface profiles given here reveals that there are a few start-up transient waves. These transient waves were generated early in the test runs and quickly moved downstream. It was found that these transient waves do not adversely affect the results, due to the long length of time for them to reach the moving obstruction and its associated wave train.

\section{II.2.1.2 Discretization of the Numerical Tank}

Nodes were placed on the boundary to form 509 panels defining the fluid domain. With this number of nodes (509) a typical simulation on one RS-6000 processor would take about 24 hours to run. Hence, this is the largest domain size practical for a parametric study. Of the 509 total panels, 299 formed the free surface. There were five panels on each of the vertical ends. 179 panels made up the flat bottom boundary and were arranged such that 90 panels were to the left of the obstruction and 89 were to the right of the obstruction. The remaining 20 panels defined the surface of the obstruction itself. The nodes were equally spaced over each segment of the fluid boundary (free 
surface, vertical walls, the obstruction, and the flats to either side of the obstruction) to create uniformly long panels. The node and panel layout described above was used for the entire parametric study. Other node layouts were tried. It was found that the results did not change appreciably for reasonable panel distributions. The distribution described above was adopted as the all around best.

The positions of the nodes making up the obstruction were continuously updated as it was "towed" to the left end of the tank. As the obstacle moved the flat bottom segments to either side changed in length accordingly. To maintain equal panel lengths over each of these two segments, the nodes were redistributed at each time step. The nodes on the vertical boundaries were also redistributed to maintain equal panel spacing at each time step. Nodes on the free surface were smoothed using the smoothing technique presented in section I.2.2.1 of this thesis.

For simplicity, this panel distribution was held fixed as the tank length was varied to produce finer, more accurate, discretizations. For most runs where the free surface was only moderately complex, a tank length of 75 times the initial depth was used. The leading edge of the obstruction for this tank length was 50 times the depth from the upstream (left) boundary. When the free surface response became very complex, especially in the case of wave breaking, a shorter tank length of 50 times the depth was used. For this tank length, the obstruction was started 30 times the depth from the upstream boundary. With a shorter tank length, the average panel size becomes dramatically smaller. This produces highly accurate results for the free surface response, while limiting the total time the simulation can be run before the obstruction reaches the left end of the tank. When long simulation times were desired, a tank length of 100 times the initial depth was used. In this case the obstruction was started 75 times the initial depth from the left boundary. Long simulation times were required to show periodic soliton generation in the subcritical regime and breaking of the upstream soliton in the transcritical regime. 


\section{II.2.1.3 Calculation of the forces}

The pressure coefficient over the surface of the structure is found using Bernoulli's equation:

$C_{P}=\frac{P}{\rho g h}=-\frac{\partial \varphi}{\partial t}-\frac{V^{2}}{2}-(y-\eta)$

The time derivative of the velocity potential, $\varphi_{\mathrm{t}}$, is found by observing that the time

derivative of the complex velocity potential, $\beta_{\mathrm{t}}$, is analytic in the fluid domain. Therefore, at each time step, the same numerical procedure that was used to determine $\beta$ is repeated to evaluate $\beta_{t}$. The lift coefficient acting on the semicircular structure is simply the integral of the pressure over the surface $\mathrm{C}_{\mathrm{S}}$ of the structure:

$C_{L}=\frac{\text { Lift }}{\rho g h^{2}}=-\int_{C_{S}} C_{p} d x$

Applying the trapezoidal rule to the integral gives:

$C_{L}=\sum_{i=1}^{n_{s t r}} \frac{\left(C_{P_{i}}+C_{P_{i+1}}\right)}{2}\left(x_{i+1}-x_{i}\right)$

where $n_{\text {str }}$ is the number of nodes on the obstacle.

The use of Bernoulli's equation in a similar manner to find the drag has been found to produce inaccuracies due to cancellation of the pressures on opposite sides of the structure. A more accurate equation for the steady state pressure coefficient was derived under the assumption that for a given point on the obstacle, the value of the velocity potential does not change with time. Observation of the numerical results confirmed that this is a valid assumption after the first few time steps. This assumption implies: 
$\left.\frac{\partial \varphi}{\partial t}\right|_{m}=\frac{\partial \varphi}{\partial t}-\frac{\partial \varphi}{\partial x} U_{B} \approx 0$

or: $\frac{\partial \varphi}{\partial x}=\frac{1}{U_{B}} \frac{\partial \varphi}{\partial t}$

where the subscript $m$ refers to a coordinate frame moving with the obstacle.

In view of the no penetration condition (1):

$0=-U_{B} \cos \vartheta+\frac{\partial \varphi}{\partial x} \cos \vartheta+\frac{\partial \varphi}{\partial y} \sin \vartheta$

or: $\frac{\partial \varphi}{\partial y}=\frac{U_{B}}{\tan \vartheta}-\frac{\partial \varphi}{\partial x} \frac{1}{\tan \vartheta}$

After substituting (13) and (14) into Bernoulli's equation, and canceling terms due to the symmetry of the obstacle, the following equation for the pressure coefficient can be found:

$C_{P}=\frac{\partial \varphi}{\partial t}\left[\frac{1}{(\tan \vartheta)^{2}}-1\right]-\frac{\left(\frac{\partial \varphi}{\partial t}\right)^{2}}{2 \cdot U_{B}^{2} \cdot(\sin \vartheta)^{2}}-\frac{U_{B}^{2}}{2 \cdot(\tan \vartheta)^{2}}+h$

where $\theta$ goes from zero at the leading edge of the structure to $\pi$ at the trailing edge of the

structure, $U_{B}$ is the upstream Froude number, and $h$ is the depth. Equation (8) is singular when theta equals zero or $\pi$. For these points:

$C_{P}=\frac{U_{B}^{2}}{2}+h$

The drag coefficient at steady state may be found by taking the following integral over the surface of the obstacle: 
$C_{d}=\frac{\operatorname{Drag}}{\rho g h} \int_{\vartheta=0}^{\pi} C_{p}\left(\vartheta, \frac{\partial \varphi}{\partial t}\right) d y$

Applying the trapezoidal rule to the integral yields:

$C_{d}=\sum_{i=1}^{n_{s t r}} \frac{\left(C_{P_{i}}+C_{P_{i+1}}\right)}{2}\left(y_{i+1}-y_{i}\right)$

\section{II.2.1.4 Calculation of the energy in the tank}

The total non-dimensional potential energy in the tank per unit tank width is found by taking the following integral over the free surface $\mathrm{C}_{\mathrm{F}}$ :

$P E=\frac{1}{2} \int_{C_{F}} y^{2} \cdot n_{y} \cdot d s=\frac{1}{2} \int_{C_{F}} y^{2} \cdot d x$

This integral may be discretized to give the following finite sum:

$P E=\frac{1}{2} \sum_{i=1}^{n_{1}-1}\left(x_{i}-x_{i+1}\right) \times\left(\frac{y_{i}+y_{i+1}}{2}\right)^{2}$

where $n_{1}$ is the total number of nodes on the free surface. The total non-dimensional kinetic energy per unit width in the tank can be found using the following formula developed by Vinje and Brevig ${ }^{30}$ :

$K E=\frac{1}{2} \int_{C} \varphi \cdot d \psi$

In discretized form:

30 Vinje, T. and Brevig, P., "Breaking waves on finite water depths. A numerical study.", The Ship Research Institute of Norway, 1981. 
$K E=\frac{1}{4} \sum_{i=1}^{m_{0}}\left(\varphi_{i}+\varphi_{i+1}\right) \times\left(\psi_{i+1}-\psi_{i}\right)$

where $\mathrm{m}_{\mathrm{o}}$ is the total number of nodes in the tank. The total energy in the tank is simply the sum of the kinetic and potential energies.

The drag coefficient may also be found using the principle of energy conservation in the tank at each time step. The drag coefficient may be calculated as follows:

$C_{d}=\frac{1}{U_{B}} \frac{d(K E+P E)}{d t}$

This method of determining the drag coefficient agrees well with the drag coefficient obtained using equation (10) for all cases, confirming the accuracy of the numerical results. As time increases, the use of equation (16) to evaluate the drag is not very accurate due to the loss of energy in the tank through the open boundaries. 


\section{II.3 Numerical Results}

Numerical simulations were performed for values of the non-dimensional obstacle height between 0.05 to 0.9 in increments of 0.1 . For each obstacle height, results were obtained for Froude numbers of $0.05,0.15,0.95,2.5$, and from 0.25 to 2.0 in increments of 0.25 . This effort constitutes a total of 120 runs to map out the free surface response for Froude numbers up to 2.5 and obstruction heights up to $90 \%$ of the flow depth.

\section{II.3.1 Free Surface Profile}

Figure II-3 shows the different regions of the free-surface response in the (Fn, $\alpha)$ parameter space.

\section{Figure II-3: Wave breaking region results (pdf, $157 \mathrm{~KB}$ ).}

The results can be separated into two categories depending on whether or not wave breaking occurs. Due to the inviscid nature of the fluid dynamics formulation, the computations break down when a wave breaks. When this occurs, the run is shortened considerably and no steady states are approached. When wave breaking does not occur three distinct flow regimes were identified: subcritical, transcritical, and supercritical. When wave breaking occurs, it may be of any type: spilling, plunging, or surging. As shown in Figure II-3, surging type breaking occurs for values of $\alpha$ greater than 0.7 . Plunging breaking is observed in most cases, while spilling type breaking is confined in a narrow region close to the subcritical and transcritical non-breaking regimes. Finally, in a small region in the transcritical regime, the upstream soliton breaks.

Figures 4, 5, 6, 8, 9, 10, and 11 show sample transient free surface profile results. In these plots, the free surface profile is shown for successive time steps. Each profile line has been displaced in the y direction a uniform amount to give the appearance of wave motion in three dimensions where the third dimension represents time. 


\section{II.3.1.1 When wave breaking does not occur}

When wave breaking does not occur, three distinct flow regimes were identified: subcritical, transcritical and supercritical. The following sections describe in detail the free surface profile characteristics for each of the flow regimes.

\section{II.3.1.1.1 Subcritical}

Figure II-4 shows a sample free surface profile for the subcritical case.

Figure II-4: Sample free surface profile plot for subcritical flow (pdf, $108 \mathrm{~KB}$ ).

As Figure II-4 indicates, on the free surface, solitary waves are generated upstream of the obstacle and a stationary (with respect to the obstacle) wave train develops downstream. The solitary waves are generated at a constant period while their amplitude decays gradually. As each soliton progresses upstream, its amplitude decreases while its wavelength and speed increase. Due to this increase in speed with time, the distance between successive crests in the train of solitons is always increasing. Consequently, the solitons spread out rapidly. As time goes on, the amplitude of the emitted solitons decays, leaving a steady state flat free surface profile ahead of the obstacle.

The stationary wave train continually produces downstream waves. Growth of the wave train occurs at the downstream end. Initial small amplitude ripples form larger waves, matching those further upstream in the wave train. Eventually the heights and wavelengths of these waves become steady. An oscillation is seen in the amplitude of the wave crests. As time goes on there appears to be a long wavelength, low amplitude downstream traveling wave superimposed on the wave train.

As the Froude number is increased, there is a decrease in the upstream soliton emission frequency and speed. As the Froude number is further increased towards 1, both the frequency and speed diminish to zero. At this point a single soliton is generated and is stationary with respect to the moving obstacle. 


\section{II.3.1.1.2}

Transcritical

In the transcritical regime, upstream solitary waves are periodically generated. The flow never reaches steady state. Figure II-5 is a sample free surface profile plot for transcritical flow.

Figure II-5 Sample free surface profile plot for transcritical flow (pdf, $67 \mathrm{~KB}$ ).

Shortly after startup, the first wave of the downstream wave train begins to move downstream. In doing so, a flat, wave-less region downstream of the obstruction is formed. The steady state length of the flat region increases with the Froude number.

\section{II.3.1.1.3}

\section{Supercritical}

As the flow becomes supercritical a constantly elongating trough forms behind a stationary precursor soliton. Figure II-6 is a sample free surface profile plot for supercritical flow.

Figure II-6: Sample free surface profile plot for supercritical flow (pdf, $32 \mathrm{~KB}$ ).

Any initially produced waves are quickly swept downstream. In the steady state, the free surface behind the obstruction is completely flat. The depth of the flat region decreases with increasing Froude number. In the case of very high Froude numbers, the free surface returns to its initial elevation downstream of the obstacle. This is the same free surface profile as the supercritical flow case in the steady state literature.

\section{II.3.1.1.4}

Overall characteristics

Figure II-7 is a plot of the height of the initial upstream advancing soliton as a function of the non-dimensional obstacle height for various values of the Froude number.

Figure II-7: Plot of the height of the initial upstream advancing soliton as a function of the non-dimensional obstacle height $\alpha$ for different values of the Froude number ( $p d f, 8$ $\underline{K B})$.

In each case, the height of the soliton was measured at steady state or just before wave breaking occurred. In general, the soliton height increases with the Froude number and 
the obstruction height. The only exception occurs in the transcritical regime where upstream breaking waves were encountered. In this region, the soliton height increases until it eventually forms a forward breaking wave.

\section{II.3.1.2 Wave breaking}

\section{II.3.1.2.1}

Downstream breaking

In all cases, wave breaking occurs in the first wave downstream of the obstruction. When wave breaking occurs, it may follow any pattern: spilling, plunging, or surging. The transition from one breaking pattern to another is smooth. Spilling waves develop symmetrically. The crest becomes sharper and sharper until the peak spills to one side and the wave breaks. Plunging breakers do not form symmetrically. The crest curls over towards the obstacle and the free surface overturns into itself. Surging breakers are seen as the collapse of a nearly vertical hydraulic jump.

Figures II-8, II-9, and II-10 show typical free surface profiles for spilling, plunging, and surging breakers, respectively.

Figure II-8: Sample free surface profile plot of a spilling type breaking wave (pdf $17 \mathrm{~KB}$ ).

Figure II-9: Sample free surface profile plot of a plunging type breaking wave (pdf, 15 $\underline{K B})$.

Figure II-10: Sample free surface profile plot of a surging type breaking wave (pdf, 16 $\underline{K B})$

When downstream plunging or surging wave breaking occurs, the wave breaks towards the obstacle. The regions where each breaking type occurs are shown in Figure II-3. The plunging type of breaking wave predominates. As the obstruction height is increased past 0.7, the plunging wave gradually becomes a surging wave. For subcritical Froude numbers, a thin region associated with spilling breaking exists close to the subcritical and transcritical non-breaking regimes. 


\section{II.3.1.2.2}

\section{Upstream breaking}

Upstream breaking of the soliton occurs in a small region in the transcritical flow regime. Figure II-11 shows the evolution of the free surface for the case of upstream breaking.

\section{Figure II-11: Sample free surface profile plot of an upstream breaking wave (pdf. 14} KB).

As shown in Figure II-11, the upstream soliton grows in height and then splits into two solitons. The leading soliton continues to grow in height as it moves upstream, away from the obstruction. At some distance from the obstruction it reaches a critical height and plunges forward. This type of breaking is only seen after especially long times when compared to downstream breaking. Non-dimensional times for this type of breaking begin at 30 and go up to about 55 . These excessively long times are in some cases too high to be achieved in the simulation. The work performed by Zhu and Zhang ${ }^{22}$ did not show the presence of these waves. It is suspected that the reason for this discrepancy is that sufficiently long times were not attained in the numerical simulation to reveal upstream breaking.

\section{II.3.2 Forces on the Structure}

\section{II.3.2.1 Transient drag behavior}

Figure II-12 contains a plot of the drag on the structure, as a function of time, for subcritical flow.

Figure II-12: Plot of the lift and drag coefficients on the structure, as functions of time, for subcritical flow ( $p d f, 38 \mathrm{~KB}$ ).

In subcritical flow, the drag oscillates periodically before converging to a steady state. Each of the drag maxima corresponds to the time of upstream traveling soliton emission. Hence, the period of the oscillations in the drag is equal to the soliton emission period. As mentioned earlier, this period increases to infinity as the Froude number increases to 
one. The amplitude of these oscillations approaches zero as the height of the solitons decays to zero. After a sufficiently long time, the drag converges to a steady state value.

Also shown in Figure II-12 is a plot of the $\frac{\partial \varphi}{\partial t}$ term. It is seen that this term is negligible after the first few time steps. This verifies the validity of the assumption leading to equation (6).

Figure II-13 contains a plot of the drag on the structure, as a function of time, for supercritical flow.

Figure II-13: Plot of the lift and drag coefficients on the structure, as functions of time, for supercritical flow ( $p d f, 18 \mathrm{~KB})$.

In supercritical flow, the drag goes through an initial maximum before slowly decaying to a steady state. No periodic oscillations are seen in the drag in the supercritical regime. When wave breaking occurs, the transient behavior described above is simply truncated at the point where the wave breaks.

\section{II.3.2.2 Steady state drag}

In the subcritical and supercritical regimes, when no wave breaking occurs, the solution for the drag will converge to a steady state after a sufficiently long time. In general, for very high supercritical and low subcritical Froude numbers, the drag converges quickly. As the Froude number approaches the transcritical regime (from either side), the rate of convergence decreases rapidly.

Figure II-14 is a plot of the steady state drag as a function of non-dimensional obstacle height for various Froude numbers.

\section{Figure II-14: Plot of the steady state drag as a function of non-dimensional obstacle height for various Froude numbers (pdf, $25 \mathrm{~KB}$ ).}

Higher obstacle heights always produce more drag than lower ones at the same Froude number. It appears that the steady state drag is exponentially related to the height of the obstacle. In the case of subcritical flow, the steady state drag increases with the Froude 
number. For example, the steady state drag for an obstruction height that is $20 \%$ of the flow depth is about 23 times greater for a Froude number of 0.5 than for a Froude number of 0.25 .

In the supercritical flow regime the steady state drag actually decreases as the Froude number is increased. It is also possible for the drag for supercritical flow to be less than that for subcritical flow, obstruction heights being equal. The steady state drag for a Froude number of 1.50 is about 3.9 times greater than that for a Froude number of 2.5 , at a non-dimensional obstacle height of 0.40 .

\section{II.3.2.3 Transient lift behavior}

Periodic oscillations are seen in the lift for subcritical flow. These oscillations are about 90 degrees out of phase with the oscillations in the drag. After a sufficiently long time, the amplitude decays to a steady state value. Figure II-12 contains a sample plot of the lift as a function of time for subcritical flow. Note that the lift in some cases is negative. This is due to the strong negative contribution of the hydrostatic pressure to the lift. In subcritical flow, the hydrostatic contribution can be as much as $96 \%$ of the total lift.

In the supercritical flow case, the lift goes through a sharp initial maximum before decaying to a steady state. Figure II-13 includes a sample plot of the lift as a function of time for supercritical flow. In supercritical flow the hydrostatic contribution can be as much as $55 \%$ of the total lift.

\section{II.3.2.4 Steady state lift}

Figure II-15 is a plot of the steady state lift as a function of the structure for various Froude numbers.

Figure II-15: Plot of the steady state lift as a function of the structure for various Froude numbers ( $p d f .5 \mathrm{~KB}$ ). 
In the case of supercritical flow, the steady state lift appears to go through a maximum value at some obstruction height. The location of this maximum appears to shift toward higher values of the obstacle height with increasing Froude number. For subcritical flow, on the other hand, the lift always decreases with increasing obstacle height. In all cases, the lift is higher for higher Froude numbers. 


\section{II.4 Conclusions}

A mixed Eulerian-Lagrangian numerical method was employed to study the freesurface flow over a bottom obstruction in two dimensions. The problem was solved in the time domain, which allows the prediction of a number of transient phenomena such as the generation of upstream advancing solitary waves as well as the simulation of wave breaking. A parametric study was performed for a range of values of the depth-based Froude number up to 2.5 and non-dimensional obstacle heights $\alpha$ up to 0.9. Different breaking and non-breaking flow regimes were identified. A systematic study was undertaken to define the boundaries of each type of flow pattern and to determine the drag and lift coefficients, free surface profile characteristics and transient behavior. 


\section{Appendix A: ABAQUS Static Analysis Model}

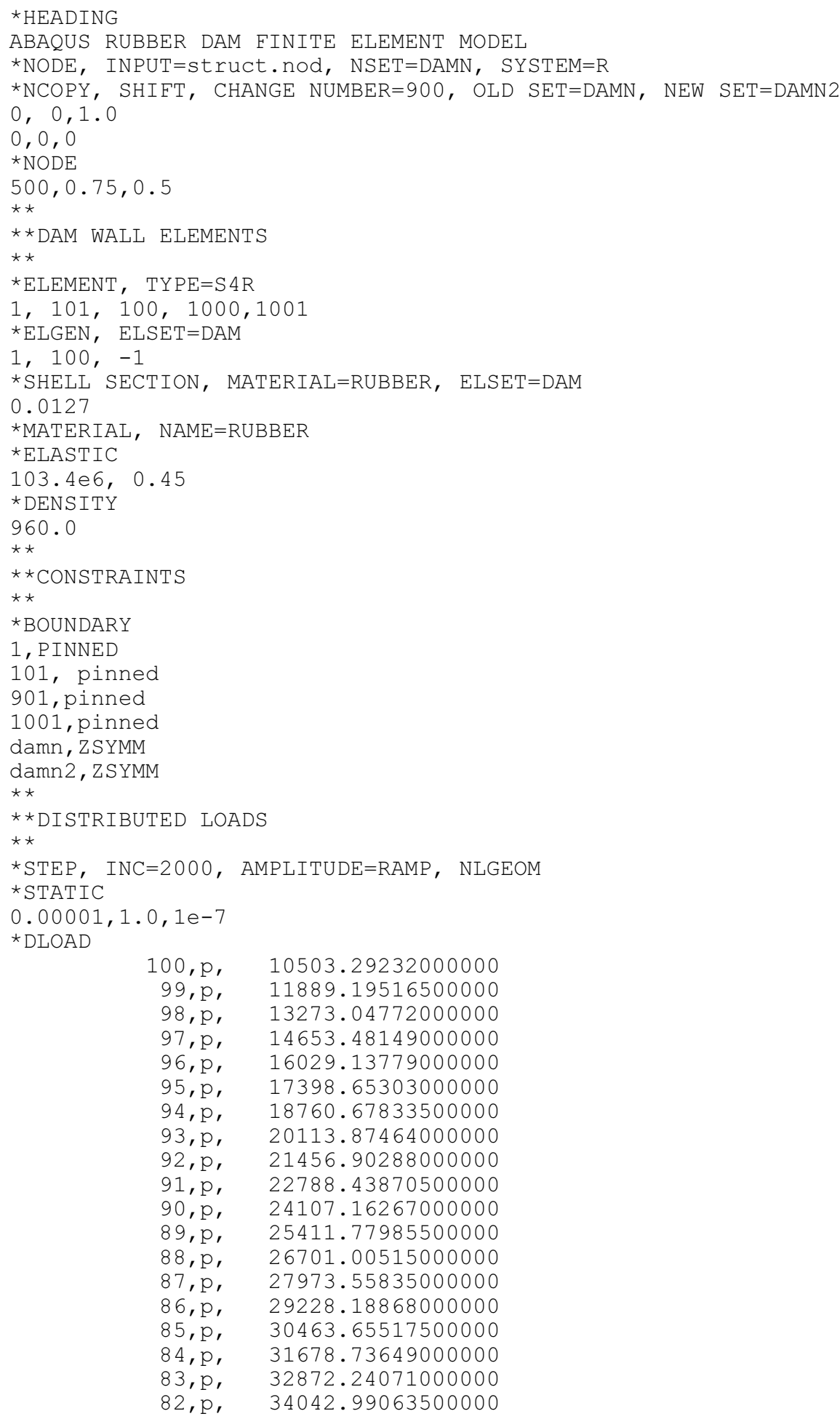




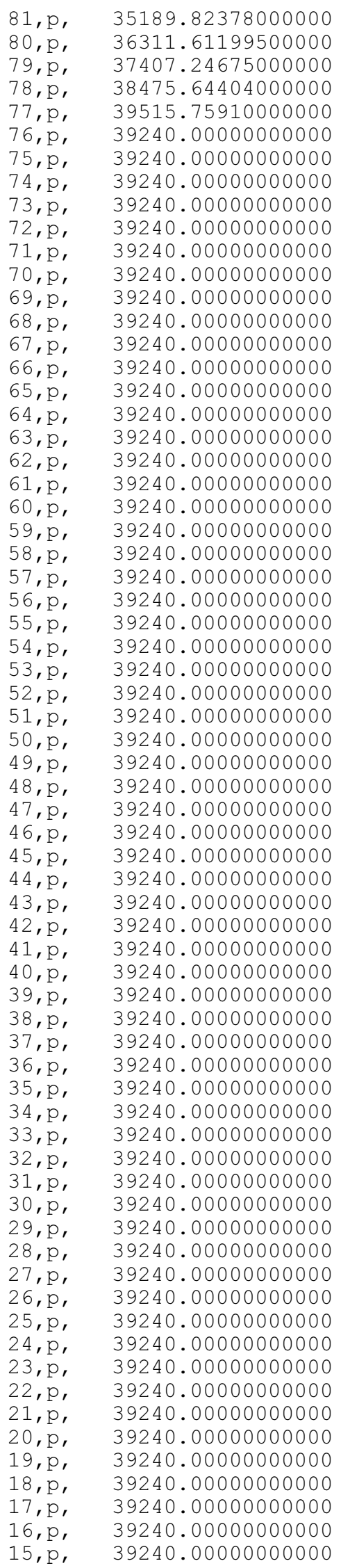




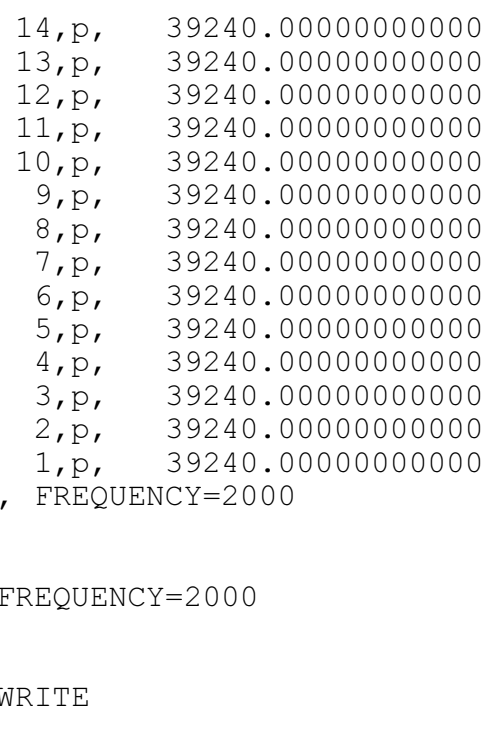




\section{Appendix B: ABAQUS Dynamic Analysis Restart File}

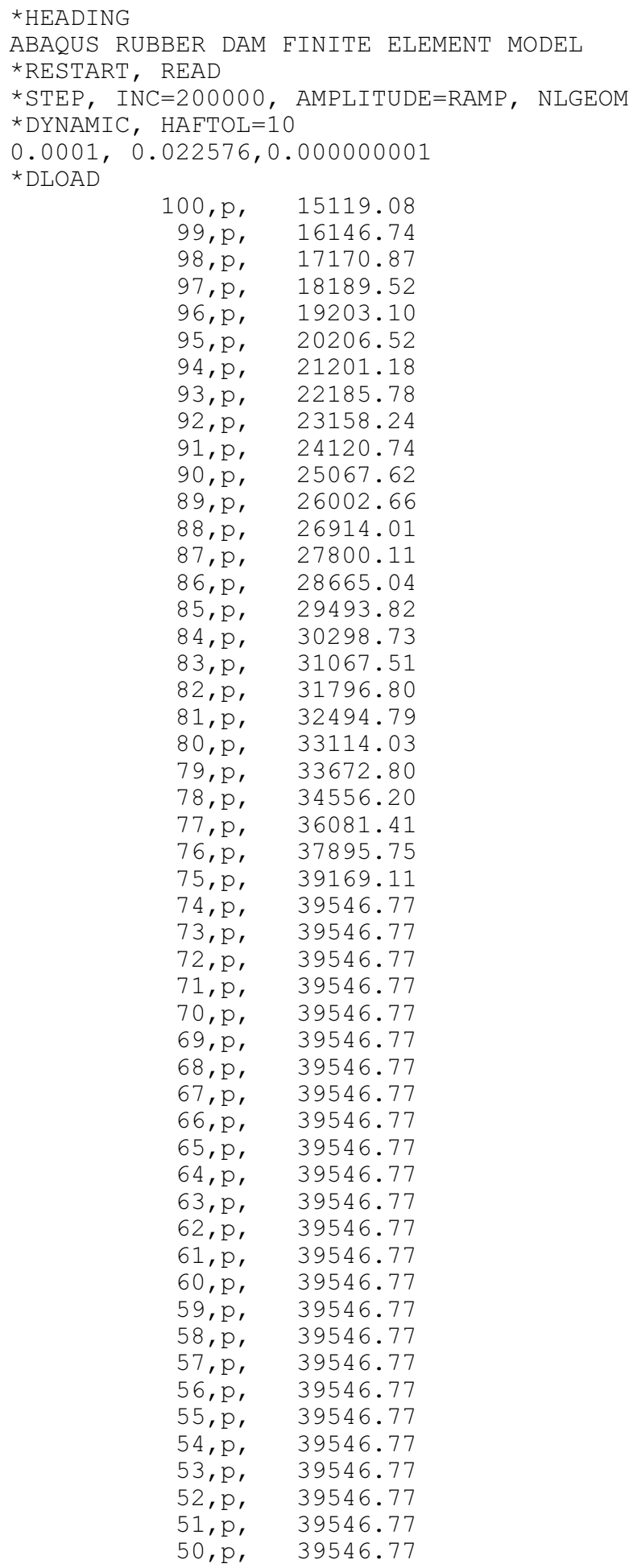




$$
\begin{array}{ll}
\text { 49, } \mathrm{p}, & 39546.77 \\
48, \mathrm{p}, & 39546.77 \\
47, \mathrm{p}, & 39546.77 \\
46, \mathrm{p}, & 39546.77 \\
45, \mathrm{p}, & 39546.77 \\
44, \mathrm{p}, & 39546.77 \\
43, \mathrm{p}, & 39546.77 \\
42, \mathrm{p}, & 39546.77 \\
41, \mathrm{p}, & 39546.77 \\
40, \mathrm{p}, & 39546.77 \\
39, \mathrm{p}, & 39546.77 \\
38, \mathrm{p}, & 39546.77 \\
37, \mathrm{p}, & 39546.77 \\
36, \mathrm{p}, & 39546.77 \\
35, \mathrm{p}, & 39546.77 \\
34, \mathrm{p}, & 39546.77 \\
33, \mathrm{p}, & 39546.77 \\
32, \mathrm{p}, & 39546.77 \\
31, \mathrm{p}, & 39546.77 \\
30, \mathrm{p}, & 39546.77 \\
29, \mathrm{p}, & 39546.77 \\
28, \mathrm{p}, & 39546.77 \\
27, \mathrm{p}, & 39546.77 \\
26, \mathrm{p}, & 39546.77 \\
25, \mathrm{p}, & 39546.77 \\
24, \mathrm{p}, & 39546.77 \\
23, \mathrm{p}, & 39546.77 \\
22, \mathrm{p}, & 39546.77 \\
21, \mathrm{p}, & 39546.77 \\
20, \mathrm{p}, & 39546.77 \\
19, \mathrm{p}, & 39546.77 \\
18, \mathrm{p}, & 39546.77 \\
17, \mathrm{p}, & 39546.77 \\
16, \mathrm{p}, & 39546.77 \\
15, \mathrm{p}, & 39546.77 \\
14, \mathrm{p}, & 39546.77 \\
13, \mathrm{p}, & 39546.77 \\
12, \mathrm{p}, & 39546.77 \\
11, \mathrm{p}, & 39546.77 \\
10, \mathrm{p}, & 39546.77 \\
9, \mathrm{p}, & 39546.77 \\
8, \mathrm{p}, & 39546.77 \\
7, \mathrm{p}, & 39546.77 \\
6, \mathrm{p}, & 39546.77 \\
5, \mathrm{p}, & 39546.77 \\
4, \mathrm{p}, & 39546.77 \\
3, \mathrm{p}, & 39546.77 \\
2, \mathrm{p}, & 39546.77 \\
1, \mathrm{p}, & 39546.77 \\
\mathrm{~F}, &
\end{array}
$$

*NODE FILE, EREQUENCY $=2000$

$\mathrm{U}, \mathrm{V}, \mathrm{COORD}$

${ }^{\star} \mathrm{EL}$ FILE, FREQUENCY $=2000$

$\mathrm{S}$

COORD

*RESTART, WRITE, OVERLAY

*END STEP 


\section{Vita}

\section{KRISTEN MARY LOWERY}

Originally from Alexandria Virginia, I attended TC Williams High School. My grandfather, Glen Scillian, was a long time radio controlled aircraft enthusiast. Early in his modeling career, he designed many amazing flying machines. Among these were a small autogyro (unusual for it's time) and a flying scale model of the Wright brothers revolutionary plane. The scale drawings of the Wright plane were taken directly from the original patents, and the finished model was put on display in the newly constructed Dulles International Airport. I adopted his love of flight and constructed several remote controlled models from my own designs.

During the summer of 1989, I participated in the George Washington University engineering apprentice program and received my first taste of engineering. This program placed me in an apprenticeship position at The Naval Research Laboratory in Washington DC. While there, I conducted spectrographic research on high temperature superconductors. I enjoyed the time I spent there very much and managed to save up some money to attend Virginia Tech the following year. My dreams of flight and interest in engineering led me to choose aerospace engineering as my major field of study.

While attending Virginia Tech, I participated in the CO-OP education program at General Dynamics, Electric Boat Division. At Electric Boat, I worked primarily on the initial Sea Wolf nuclear powered submarine. My biggest project while there was the development of a dockside anti-fouling device for the ship's propulsor. This device was intended to be mounted on the twenty-foot diameter propulsor while the ship was dockside to prevent the build up of marine growth. During my first session at Electric Boat I researched and developed the concept and made a design proposal to the U.S. Navy. This proposal was approved shortly before I returned for a second session, and I completed the detailed design and structural analysis. 
Another project I worked on was the defect analysis of a 1.5" thick GRP (glass reinforced plastic) rope guard. These are large composite fairings mounted just forward of a submarine propeller. There were problems fabricating the unusually thick laminates, especially during the consolidation stage. The finished parts ended up with many entrained air pockets. I was assigned to perform structural analysis of the defective parts to determine whether they were adequate for use on the ship. Overall, I had many good experiences at Electric Boat, and ocean engineering became a definite possibility as a career choice.

After returning to college, I took up ocean engineering as a second major and graduated, summa cum laude, on May 11, 1996 with two Bachelor of Science degrees. I felt even with two pieces of paper in hand that I still didn't possess sufficient skills to become an engineer. I decided to return to Virginia Tech the following fall to pursue a Master of Science degree in aerospace engineering. 